NBER WORKING PAPER SERIES

\title{
GOOD VERSUS BAD DEFLATION: LESSONS FROM THE GOLD STANDARD ERA
}

\author{
Michael D. Bordo \\ John Landon Lane \\ Angela Redish \\ Working Paper 10329 \\ http://www.nber.org/papers/w10329
NATIONAL BUREAU OF ECONOMIC RESEARCH
1050 Massachusetts Avenue
Cambridge, MA 02138
February 2004

This paper was prepared for the Federal Reserve Bank of Cleveland's 'Conference on Low Inflation Economies', November 20-21 2003. For helpful comments we thank: Tam Bayoumi, Jon Faust, Dale Henderson, Ulrich Kohli, Andy Levin, Marc Wiedenmeir, and our discussants: Larry Christiano and Francois Velde. For able research assistance we thank Sonal Dhingra. The views expressed herein are those of the authors and not necessarily those of the National Bureau of Economic Research.

(C2004 by Michael D. Bordo, John Landon Lane, and Angela Redish. All rights reserved. Short sections of text, not to exceed two paragraphs, may be quoted without explicit permission provided that full credit, including (C) notice, is given to the source. 
Good versus Bad Deflation: Lessons from the Gold Standard Era

Michael D. Bordo, John Landon Lane, and Angela Redish

NBER Working Paper No. 10329

February 2004

JEL No. E3, N20

\begin{abstract}
Deflation has had a bad rap, largely based on the experience of the 1930's when deflation was synonymous with depression. Recent experience with declining prices in Japan and China together with the concern over deflation in Europe and the United States has led to renewed attention to the topic of deflation. In this paper we focus our attention on the deflation experience of the United States, the United Kingdom, and Germany in the late nineteenth century during a period characterized by low deflation, rapid productivity growth, positive output growth, and where many nations had a credible nominal anchor based on gold: circumstances which have resonance with the world of today. We identify aggregate supply, aggregate demand, and money supply shocks using a structural panel vector autoregression. We then use historical decompositions to investigate the impact that these structural shocks had on output and prices. Our findings are that the deflation of the late nineteenth century reflected both positive aggregate supply shocks and negative money supply shocks. However, the negative money supply shocks had little effect on output. This we posit is because the aggregate supply curve was very steep in the short run during this period. This contrasts greatly with the deflation experience during the Great Depression. Thus our empirical evidence suggests that deflation in the nineteenth century was primarily good.

$\begin{array}{lll}\text { Michael D. Bordo } & \text { John S. Landon-Lane } & \text { Angela Redish } \\ \text { Department of Economics } & \text { Department of Economics } & \text { Department of Economics } \\ \text { Rutgers University } & \text { Rutgers University } & \text { University of British Columbia } \\ \text { New Brunswick, NJ 08901 } & \text { New Brunswick, NJ 08901 } & \text { Vancouver, B.C. } \\ \text { and NBER } & \text { lane@econ.rutgers.edu } & \text { Canada, V6T 1Z1 } \\ \text { bordo@econ.rutgers.edu } & & \text { anji@econ.ubc.ca }\end{array}$
\end{abstract}




\section{Introduction}

Recent concerns by the FOMC at its meeting in May 2003 that the "balance of risks in the US had shifted in favor of deflation", similar concerns raised by an IMF Report on Deflation (2003) over the risk of deflation in Europe, especially Germany and Switzerland, and the experience of declining price levels in China and Japan has sparked new interest in the subject of deflation. In this paper we examine the issue from an historical perspective. We focus on the experience of deflation in the late nineteenth century when most of the countries of the world adhered to the classical gold standard. The period 1880-1914 was characterized by two decades of secular deflation followed by two decades of secular inflation.

The price level experience of the pre-1914 period has considerable resonance for recent concerns over the possibility of deflation's re-emergence. Four elements of the earlier experience are relevant for today's environment: deflation was relatively low (1$3 \%$ in most countries); productivity advance was rapid; the real economy was growing; and the price level was anchored by a credible nominal anchor - adherence to gold convertibility.

Deflation has had a 'bad rap'. Possibly as a consequence of the combination of deflation and depression in the 1930s, deflation is associated with (for some, connotes) depression. In contrast, a basic tenet of monetary theory - the Friedman rule - suggests that deflation (albeit perfectly anticipated) is an outcome of optimal monetary policy. On the face of it, the evidence from the late 19th century was mixed: on the one hand, the mild deflation in the period 1870 - 1896 was accompanied by positive growth in many countries, however, growth accelerated during the period of inflation after 1896.

We distinguish between good and bad deflations. In the former case, falling prices may be caused by aggregate supply (possibly driven by technology advances) increasing more rapidly than aggregate demand. In the latter case, declines in aggregate demand outpace any expansion in aggregate supply. For example, negative money shocks that are 
non-neutral over a significant period would generate a 'bad' deflation. This was the experience in the Great Depression (1929-33), the recession of 1919-21, and may be the case in Japan today. ${ }^{1}$ There is also a third possibility - the Classical case where deflation - for example caused by negative money shocks - is neutral, as when monetary neutrality holds. $^{2}$

We focus on the price level and growth experience of the United States, the U.K. and Germany from 1880-1913. All three countries adhered to the international gold standard, under which the world price level was determined by the demand and supply of monetary gold, and each member followed the rule of maintaining convertibility of its national currency into a fixed weight of gold. This meant that the domestic price level was largely determined by international (exogenous) forces.

We proceed by identifying separate 'supply' shocks, money supply shocks and 'non-monetary' demand shocks using a Blanchard-Quah methodology. We identify the shocks by imposing long run restrictions on the impact of the shocks on output and prices, and then do a historical decomposition to examine the impact of each shock on output and the price level. ${ }^{3}$ We present three sets of empirical results: firstly, results for each country from estimating a panel over the period 1880-1913, then results from estimating a panel over only the deflationary period, 1880-96, and finally results from the entire period in a model in which gold supply shocks are included as an exogenous variable. Contrasting the first two series of results enables us to discuss the symmetry between the deflationary and inflationary period, while in the third set we separate money supply shocks coming from gold shocks from those coming from intermediation shocks.

\footnotetext{
${ }^{1}$ The traditional explanation for this non-neutrality is nominal rigidities and more recently balance sheet effects are also ascribed an important role (Bernanke, 1983).

${ }^{2}$ Many people take issue with the term "good" deflation on the view that any departures from price stability are problematic. An alternative set of terms that we could use are "benign" versus "malignant" deflation or "the good, the bad and the ugly" as used by Borio and Filardo (2003). These terms connote: productivity driven deflation as used by us; low deflation and stagnation as has been the case in Japan; and the interwar experience.

${ }^{3}$ A similar methodology is followed in Bordo and Redish (2004). The results of the historical decompositions for the money stock, as well as the results from forecast error variance decompositions, are not presented in this paper for space reasons, but are available from the authors on request. The results are consistent with those reported in this text.
} 
The paper begins by briefly describing the data and historical environment. We then discuss the empirical methodology to be used. Our empirical analysis is presented in the next three sections, and the final section discusses the results and their implications and limitations.

Focussing on our interest in the deflationary episode, our results in a nutshell suggest that the deflation was generated by monetary factors, but that these monetary factors do not explain much of the behaviour of output. Output was determined by nonmonetary factors and the deflation was essentially good or neutral.

\section{The context}

Figure 1 illustrates the behaviour of the money stock, prices (GDP deflators) and real incomes in the three countries over the period 1880 - 1913. We use broad money (M2) as our measure of money stock, real GDP as our measure of real income and the GDP deflator as our measure of prices. ${ }^{4}$ While there are differences in the patterns there are a few common trends: price levels declined - more in the U.S. than elsewhere - over the period 1880 to the mid 1890s, and subsequently rose. The money stock rose secularly, the most pronounced rise occurring in Germany, and in the U.S. the growth rate increased after 1896. Income levels rose with a slight acceleration in the US and UK after the 1890s, but German output growth decelerated (very slightly) from its very rapid post1870s rate after the mid-1890s.

The period 1880-1913, encompassed myriad economic events. Technological changes occurred rapidly, and earlier changes were implemented at the production level. German and US growth outpaced that of England. Early historians had described the period before 1896 as a 'great depression' but more recent historiography has recast the period as one of deflation without depression (Craig and Fisher, 2000). Although there were very severe recessions, particularly in the early 1890s, secularly incomes rose.

4 Data are available from the authors on request. Sources: US - Balke and Gordon (1986); UK - Mitchell (1998); Germany - Prices: Sommariva and Tullio (1987); GDP: Mitchell (1998); Money: Deutsche Bundesbank (1976). Real output is denominated in 1913 pounds sterling while nominal money supply is denominated in current pounds sterling. The GDP deflators are used as the price series and these are based in 1913 . 
Particularly noteworthy is the transmission of business cycles across economies, with all three of our economies experiencing common cycles. ${ }^{5}$

At the monetary level there were also secular trends and cyclical fluctuations. The gold standard tied the quantity of money to the stock of gold. Figure 2 shows that world gold production was constant and relatively low from 1870 to 1890 while after the early 1890s it grew. The growth reflected gold discoveries in South Africa as well as Australia and North America.

\section{Methodology}

Our empirical analysis is grounded by a model of money supply under the gold standard. The appropriate modeling strategy depends on the time horizon of interest, whether one is interested in the very long run, the long run or business cycle frequency. The 'very long run' we consider to be a period long enough for the quantity of gold mined to respond endogenously to macroeconomic variables. ${ }^{6}$ Given the short span of data available for our empirical analysis, we do not attempt to capture effects over this period, and restrict ourselves to long run and business cycle frequencies.

The long run is defined here as a period over which purchasing power parity holds, and we model a world comprising several gold standard economies linked together by trade in gold, goods and capital. We assume that in each economy the quantity of money is a stable function of the country's stock of monetary gold, but the function is allowed to vary across countries reflecting, for example, the existence or not of a central bank, required reserve ratios, the degree of monetization and the nature of the banking system. The world price level is determined by the world demand for money (based on the determinants of velocity and aggregate income) and the supply of money (the supply being determined by stocks of gold and the nature of intermediation). Individual economies take the world price level as exogenous. For each country we identify three

\footnotetext{
${ }^{5}$ See IMF (2002) and Bergman, Bordo and Jonung (1998).

${ }^{6}$ For example, models in Bordo and Ellson (1985) and Dowd and Chappell (1997) allow the quantity of gold mined to respond endogenously to the price level, through investment in refining technologies and exploration. See also, Barro (1979) and Rockoff (1984). Rockoff argues that the increased gold production of the late $19^{\text {th }}$ century was a response to the incentive of the high real price of gold (i.e. low price level).
} 
shocks that drive the joint behaviour of prices, output and the money stock: a money supply shock, a technology shock, and a non-monetary demand shock, where the definition of each shock is implicit in the identifying assumptions described below.

We model output, prices and money supply using the following tri-variate VAR in differences:

$$
\Delta y_{t}=D_{t} \alpha+\sum_{j=1}^{p} B_{j} \Delta y_{t-j}+\varepsilon_{t},
$$

where $y_{t}=\left(\right.$ price $\left._{t}, G D P_{t}, M_{t}\right)$ and $\mathrm{D}_{\mathrm{t}}$ is a matrix of deterministic variables that includes a constant and possibly a time trend. The data are tested for the presence of a unit root and are differenced to make them stationary.

Underlying the reduced form specification, (1), is a set of structural innovations, $\mathrm{u}_{\mathrm{t}}$, that are orthogonal to each other and are related to the reduced form innovations in (1) by

$$
\varepsilon_{t}=C u_{t} .
$$

Our aim is to identify orthogonal shocks, $u_{t}$, that can be interpreted as an aggregate supply shock, a nominal money supply shock and a non-monetary aggregate demand shock. To this end, we identify $\mathrm{C}$ by imposing long-run restrictions on the structural impulse response functions implied by (1). These long-run restrictions are imposed using the method described in Blanchard and Quah (1989).

In order to exactly identify $\mathrm{C}$ for each country, we need to impose at least three independent long-run restrictions on the impulse response functions from (1). Our preferred identification is as follows: An aggregate demand shock is assumed to have zero long-run impact on output and prices. That is, the demand shock has no permanent impact on prices or output. We also assume that the aggregate supply shock, in the context of the gold standard, has no permanent impact on prices. That is, the long-run impact of an aggregate supply shock on price is zero. 
This identifying restriction follows from the fact that the countries in our sample were all strictly adhering to the gold standard during the sample period. An aggregate supply shock would be expected to initially lower the price level and increase real output. The decline in the price level would lead in turn to a gold inflow via the current account, hence raising the money supply and price level. Thus, gold flows will have the effect of causing price levels, in the absence of further shocks, to return to their original levels.

These three long-run restrictions are enough to exactly identify $\mathrm{C}$ and hence identify the structural shocks, $u_{t}$. We thus impose no restrictions on the impact of the third shock. This is the only long run influence on the price level and can be interpreted as a world price level shock or, in the context of our model, as a money supply shock. The aggregate demand shocks are presumably an aggregate of money demand shocks and temporary spending shocks, which cannot be disentangled. The effect of such an aggregate on prices and output in the short run would depend on its component mix, and we essentially treat this as a reduced form construct.

A summary of our preferred identifying restrictions is:

1. An aggregate supply shock has no long-run impact on prices.

2. An aggregate demand shock (combining the impact of velocity and spending shocks) has no long-run impact on either prices or output.

3. The long run (and short run) impact of a nominal money supply shock on money, output and prices is unrestricted.

The long-run impact of shocks to $\mathrm{u}_{\mathrm{t}}$, the structural innovation vector, is

$$
L R=(I-A(1))^{-1} C,
$$

where $A(L)=I-A_{1} L-\ldots-A_{p} L^{p}$ and $A(1)=I-\sum_{j=1}^{p} A_{j}$. Assuming that the structural innovation vector is ordered as $u_{t}=\left(\text { money shock }_{t} \text {, } \text {,upply shock }_{t} \text {, demand } \operatorname{shock}_{t}\right)^{\prime}$ then the long-run impact matrix is 


$$
L R=\left[\begin{array}{ccc}
L R_{11} & 0 & 0 \\
L R_{21} & L R_{22} & 0 \\
L R_{31} & L R_{32} & L R_{33}
\end{array}\right]
$$

In addition to our preferred identification there are other possible long-run restrictions that could have been imposed. The most likely additional restriction is money neutrality, which would imply that the long-run impact of a money shock on output is zero. The addition of this long-run restriction leads to the long-run impact matrix

$$
L R=\left[\begin{array}{ccc}
L R_{11} & 0 & 0 \\
0 & L R_{22} & 0 \\
L R_{31} & L R_{32} & L R_{33}
\end{array}\right]
$$

Clearly this leads to an over-identified system. Following the method described in Amisano and Giannini (1997), the over-identifying restrictions imposed in (5) can be tested. If this extra long-run identification cannot be rejected it will be imposed. However, we prefer not to impose money neutrality but rather allow the data to tell us if money neutrality holds during this sample. Only then do we impose this additional longrun restriction.

Another possible combination of the four long-run restrictions given in (4) and (5) would be

$$
L R=\left[\begin{array}{ccc}
L R_{11} & L R_{12} & 0 \\
0 & L R_{22} & 0 \\
L R_{31} & L R_{32} & L R_{33}
\end{array}\right]
$$

In this specification money neutrality would be imposed while the impact of the supply shock would be unconstrained. The set of constraints given in (6) exactly identify the structural shocks. If (5) is rejected we are left with a decision on whether to use (4) or (6), and opt for (4) on the basis of the historical context.

Given the small sample size inherent in the data there are efficiency gains from pooling the data and estimating a panel VAR (PVAR) given by 


$$
\Delta y_{i t}=D_{t} \alpha_{i}+\sum_{j=1}^{p} B_{i j} \Delta y_{i t-j}+\varepsilon_{i t} \quad \varepsilon_{i t} \sim N\left(0, \Sigma_{i}\right)
$$

The maintained assumption in this exercise is that the slope coefficient matrices, $\mathrm{B}_{\mathrm{ij}}$, are common across the countries in the panel. Different growth rates between countries and periods are allowed by permitting the constant terms in each VAR to be different. Also, the variance-covariance matrix of the innovations for each country specific $\operatorname{VAR}, \sum_{i}$, is allowed to differ across countries. This assumption allows for crosssectional heteroscedasticity in the data. One implication of permitting cross-sectional heteroscedasticity is that individual countries are not constrained to have the same responses to structural shocks. All that is being assumed is that all countries have the same slope coefficient matrices in the reduced form VAR. Also, the values of the slope coefficients do not change throughout the sample. These two assumptions are tested and the results of these tests are reported in Table 1 and Table 2.

The PVAR in (7) is estimated using the standard seemingly unrelated regression estimator (SURE) with cross-equation restrictions imposed as defined above. This allows us to exploit the panel structure and any contemporaneous correlation in shocks between countries to improve the efficiency of our estimates. After estimating our PVAR we then estimate $\mathrm{C}_{\mathrm{i}}$ for each country using the scoring algorithm defined in Amisano and Giannini (1997) and use these estimates to calculate structural impulse response functions for each country. Once we have $C_{i}$ we are also able to construct the structural shocks implied by (2).

The structural impulse response functions isolate the impact of each of our identified shocks on each variable. Since we impose no restrictions on the impact effects of the shocks, we can use consistency between the theoretical predictions for the impact effects and the estimated impulse response functions to make the case that our economic interpretation of the estimated shock is valid. Having made that case, the historical decompositions allow us to do the counterfactual analysis that is inherent in our questions: How would output and prices have evolved if there had been no monetary 
shocks? What were the relative contributions of money and real shocks to the late 19th century deflation? These results are reported in the next Sections.

\section{Results - Full Sample}

Prior to estimation we analyzed the time series properties of the data and concluded that all the series were I(1) and we therefore estimated the model in first differences. That is, we estimated (7). Information criteria tests suggested that a model with two lags fit the data well (that is $\mathrm{p}=2$ ), and we included a trend break in all series in 1896. Given that the series are all non-stationary and that we estimated (7), the break in trend is handled by putting a dummy variable that takes the value of 0 before 1897 and takes the value of 1 from 1897 until 1913. Clearly using two lags in (7) would have severely affected the degrees of freedom of the estimator for the individual estimation. Table 1 reports tests of slope parameter equality across the countries in the sample. That is, Table 1 reports Wald test results for the test given in (8):

$$
H_{0}: B_{i j}=B_{k j} \forall i, k \text { for each } j
$$

$v s$.

$$
H_{A}: B_{i j} \neq B_{k j} \text { for some } i, k \text { and for some } j \text {. }
$$

This test was performed using data from the whole sample (1880-1913) and using data for the deflationary sample (1880-1896). In both cases the null hypothesis could not be rejected so that our assumption of similar short-run dynamics across the countries in our panel is not rejected by the data. Given that there appears to be a trend break in 1896 a test was performed to see if there was also a structural break in the short-run dynamics of the VAR. That is, we tested to see if the estimates of $B_{i j}$ were significantly different for the two different periods. Results from these tests are reported in Table 2. For each

country individually and for the panel estimate there is no evidence of a structural break in the short-run dynamics of the system. Therefore, we account for the break in trend with intercept adjustments only.

Structural impulse response functions were estimated using identifications (4) and (5). The over-identifying restrictions in (5) were tested and these results can be found in 
Table 3. Estimating (1) using data from each country individually we see that the overidentifying restrictions are rejected for each country. When we estimate (7) using the panel estimator we see that neutrality is rejected for the US and the UK but not for Germany. Therefore we do not impose neutrality and so use identification (4) to compute the structural impulse response functions.

Structural impulse response functions showing the impact of a $1 \%$ shock are reported in Figures 3 through 5. Standard error bands show 90\% approximate asymptotic confidence intervals calculated using the method described in Amisano and Giannini (1997). ${ }^{7}$ We observe for all countries that the money supply shock has a large positive impact on output in the short run, and a much smaller (zero for Germany) long run positive impact. In the US, prices and the money stock rise proportionately in response to the money shock, though in the other countries the price effect is larger. In each case the supply shock is observed to cause a significant temporary decline in prices (recall that the long run impact is imposed to be zero). In the US, the long run income elasticity of money is roughly unitary (that is, the money stock increases proportionately with increases in income) while in Germany and the UK it is somewhat less that unitary. Consistently with the interpretation as a demand shock, the direction of the impact of the third shock is the same for prices and output. In each case the shock has a negative short run impact on prices and output, and a positive impact on money stocks, which is consistent with an interpretation that velocity shocks dominated the demand influences.

Historical decompositions for each shock are reported in Figures 6 through 8. The three panels each contain plots of three series: the actual path of the variable, a baseline - which incorporates trends and shocks before the estimated period but none of the shocks during the estimated period; and a line showing the baseline plus the effect of one of the structural shocks. If the third line lies essentially on top of the baseline, then the isolated shock had no effect on the variable, while if the third line lies on top of the actual line, it shows that the isolated shock accounts for the behaviour of the variable.

\footnotetext{
${ }^{7}$ In fact probably less than $90 \%$ given our small sample size.
} 
In all three countries the behaviour of the price level is driven by the money shock. That is, while the impulse response functions show that supply shocks have short run price effects, the quantitative impact of those effects is negligible. More germane to our interests is the behaviour of output. In the UK and Germany supply shocks explain virtually all output fluctuations. In the United States, supply shocks are the dominant driving force, however, in a number of years money supply shocks have a noticeable impact. This is consistent with the conventional wisdom that US monetary institutions exacerbated output volatility in these periods. In all countries the impact of the demand shocks was small.

The estimated structural shocks are shown in Figure 9. Consistently with our interpretation of the history of the period, the money supply shocks are correlated across the three countries, as are the supply shocks. The demand shocks are uncorrelated, suggesting that there was a significant idiosyncratic component to the temporary shocks.

Two sensitivity analyses were carried out to check the robustness of our results. First we replaced M2 with M0, the monetary base, as our measure of money stock. Second we included dummy variables for 1907 and 1908, a period of financial crisis for the countries in our sample, in the VAR. In both cases, while the magnitudes of the impulse response functions were slightly different, the qualitative results described above remain. This was the case for the benchmark VAR for the entire period and the subsequent VAR where we add in the world gold stock as an exogenous variable.

\section{Deflationary Period Results}

Using the panel consisting of the three core countries, a PVAR is estimated using data from the period 1880-1896. This period saw a substantial price deflation as seen in Figure 1. Taking into account the first three periods that are lost due to first differencing the data and the two lags used in the PVAR, there are 14 observations for each country. Clearly, this would not be enough data to estimate the VAR for each individual country in the sample. However, in the PVAR data are pooled from the three countries in the panel so that we have a total of 42 observations at our disposal. The test statistic of the 
test of slope coefficient equality across countries is 35.75 with a p-value of 0.481 (see Table 1). This means that there is no statistical evidence to suggest that we cannot pool the data for the deflationary period.

We began by testing for the over-identifying restrictions in (5), and the results are reported in Table 3. Similar to the full sample case we see that the test is rejected for the US and is not rejected for Germany. However, for the UK the p-value is now 0.08. Using the full sample in the PVAR the p-value for the UK was smaller than 0.001. Given that the point estimate of the long run impact of money on output is similar, at about $0.5 \%$, the change in the p-value is most likely due to the smaller sample size, and hence larger standard errors, rather than there being anything different for the UK in the deflationary period. We therefore proceeded by estimating the model without monetary neutrality (that is, the model of equation (4)). Figures 10-12 report the structural impulse response functions for each country.

Overall, the impulse response functions for the deflationary period have the same qualitative appearance as in the full sample. In particular, for the US and UK the impulse responses show that a money supply shock which has a given effect on the long run money stock has the same estimated impact on output in both the full sample and the deflationary sample. This is an implicit test of the symmetry of the responses in the deflationary period and inflationary period, and suggests that, for the late nineteenth/early twentieth period that we are examining, responses were symmetric in the two eras.

Finally the results of the historical decompositions of output are shown in Figures 13-15. While the sample sizes for the individual countries are small, it is clear for each country that the behaviour of prices was driven by the money shock. That is, the deflation of the late nineteenth century was generated by negative monetary shocks. The behaviour of output is again largely driven by supply shocks, although in the mid-1880s US output reflected the impact of all three types of shocks. 


\section{Results for the full period with exogenous gold shocks}

Our preferred identification, (5), is driven by the fact that during the period of our sample, the countries in our panel were all on the gold standard. We are therefore interested in knowing what role, if any, gold shocks played during this period. The model that is estimated is

$$
\Delta y_{i t}=\alpha_{i 0}+\alpha_{i 1} D_{1896 t}+\sum_{j=1}^{p} B_{j} \Delta y_{i t-j}+\sum_{k=0}^{m} \gamma_{k} \Delta \text { Gold }_{t-k}+\varepsilon_{i t}
$$

where Gold $_{\mathrm{t}}$ is the total world gold stock. ${ }^{8}$ In this specification gold is completely exogenous to the system. As noted in Section 3, at very long horizons the world gold stock may be endogenous, but given the time span of our data exogeneity is a reasonable assumption. Table 4 shows the results of a Hausman type test for exogeneity. For all countries and all variables we cannot reject the hypothesis that gold is exogenous to our variables. ${ }^{9}$ A panel VAR is estimated using (9) with slope coefficients, $B_{j}$, and the impact coefficients of gold, $\gamma_{j}$ constrained to be equal across countries. Table 1 contains the results of the Wald test that tests whether the coefficients on gold in (9) are common across the countries in the panel. The reported p-value for this test is 0.63 so the hypothesis that the gold coefficients are common across countries cannot be rejected.

Figures 16 to 18 depict the structural impulse response functions calculated using the estimates of (9). These figures are qualitatively similar to the previous impulse response functions when gold was not included into the VAR. ${ }^{10}$ Figures 20 to 22 depict the historical decompositions. Again we see that money contributes most to prices and the supply shock explains most of the observed variation in output. It is interesting to note that gold does not play an important role in the observed variation of prices and output.

\footnotetext{
${ }^{8}$ Gold data are from the US Gold Commission (1982), Vol. I Table SC-6.

${ }^{9}$ Note that the Hausman test is really a test of whether ordinary least squares provide consistent estimates of (12). To conduct the Hausman test we use $\Delta$ gold $_{t-2}$ as the instrument for $\Delta$ gold $_{t}$.

${ }^{10}$ The only qualitative difference is that the monetary shock has a small long run negative impact on German output (when we estimate over only the deflationary sample this result is overturned - see below).
} 
We have also re-estimated the model for the deflation sample alone (1880-1896), but for space reasons do not include the figures here. ${ }^{11}$ The historical decompositions for prices show that, as in the case without gold, supply shocks and the non-monetary demand shock contribute little to the behaviour of prices. But now the price level is explained in part by gold shocks and in part by domestic money shocks. Gold shocks however explain little of the output fluctuations.

Figure 19 shows the impact of a 1\% increase in gold supply on prices, output and money supply. We see that the long run impact of this gold shock is what we would expect under the gold standard. That is, the long-run impact of a $1 \%$ increase in gold supply is a $1 \%$ increase in prices, a $1 \%$ increase in money supply and no increase in output. This result suggests that our assumptions based on the gold standard are not unrealistic.

However, there is a puzzling result in that the initial impact of the gold shock on prices is negative. One reason for this may be that the gold shocks that we are observing could be price led rather than being exogenous to the system. That is, lower prices lead to gold flows that appear in the data as positive gold supply shocks. This last observation would suggest that gold is not entirely exogenous and the possible endogeneity between price and gold should be modeled explicitly. How best to model this endogeneity is a difficult question as gold supply most probably has an endogenous component and an exogenous component. This problem is left for future research.

\section{Conclusions}

Inflation rates around the globe have fallen from historically high levels in the 1970 s and 1980 s to numbers close to zero as the $20^{\text {th }}$ century ended. Indeed some countries have experienced actual deflation. Yet output growth rates remain positive. Not since the turn of the $19^{\text {th }}$ century, have economies experienced such low inflation associated with non-negative growth, and it seems natural to turn to that period to learn about macro behaviour in low inflation or possibly deflationary environments.

\footnotetext{
${ }^{11}$ Figures are available from the authors.
} 
Deflation can reflect the impact of positive aggregate supply shocks (in the absence of offsetting positive demand shocks) or negative demand shocks. In the latter case, if the aggregate supply curve is non-vertical, the deflation will be 'bad' in that it will be accompanied by negative output effects.

Our results show that the deflation in the late nineteenth century gold standard era in three key countries reflected both positive aggregate supply and negative money supply shocks. Yet the negative money shock had only a minor effect on output. This we posit is because the aggregate supply curve was very steep in the short run. Thus our empirical evidence suggests that deflation in the late nineteenth century was primarily good.

Important issues for today's environment arise from our findings. We need to be clear about what was different between the late nineteenth century environment and that of the twentieth and twenty first centuries. First, the historical era we analyze was the classical gold standard regime under which all three countries were linked together via common adherence to the gold standard convertibility rule and all faced a common money shock - the vagaries of the gold standard.

Second, aggregate supply seems to have been an important source of the shocks that we identify. This is likely in contrast to the other major deflationary episodes of the the twentieth century including: 1920-21, 1929-33, and Japan in the 1990s, which many observers posit reflected the consequences of severe monetary contraction. ${ }^{12}$ Today's environment in the US, Canada and the EU may indeed be closer to the pre-1914 era than the earlier twentieth century episodes.

Third the short run aggregate supply seems to have been very steep pre-1913. This meant that negative demand shocks did not have much of a contractionary bite. This result is in sharp contrast to the experience of 1929-33. Many attribute the catastrophic

\footnotetext{
${ }^{12}$ For a contrary view see Kehoe and Prescott (2002).
} 
declines of output in the face of monetary contraction then to the presence of nominal rigidities, in particular sticky wages (Bordo, Erceg and Evans, 2000).

Our analysis does not deal with many important issues that resonate in today's policy debate over what to do about the spectre of deflation. These include the zero nominal bound problem -- that very low inflation by reducing nominal interest rates makes it difficult to conduct monetary policy by conventional means (Orphanides, 2001). In contrast to today, in the pre-1914 era, little emphasis was placed by the policy makers in countries, like the UK and Germany, which had central banks, in using monetary policy to stimulate the real economy. Hence the zero nominal bound was not viewed as a problem.

We also do not explicitly distinguish between the effects of actual versus expected price level changes. It is unexpected deflation that produces negative consequences. However the steep slope of the aggregate supply curve revealed in our work suggests that price level changes were large anticipated. We also do not consider the efficiency aspects of deflation. According to Friedman (1969), the optimum holding of money would occur at a rate of deflation equal to the long run growth rate of real output.

Finally, although we find that pre-1914 deflation was primarily of the good variety, it doesn't mean that people felt good about it. The common perception of the $1880 \mathrm{~s}$ and $1890 \mathrm{~s}$ in all three countries was that deflation was depressing. This in turn may reflect the fact that deflation was largely unanticipated. It may also have reflected money illusion. ${ }^{13}$ This was reflected in labor strife and political turbulence. This perception can be seen in the views of US farmers who believed that the terms of trade had turned against them and workers in all three countries who did not view falling money wages as being compensated by even more rapidly falling commodity prices. It is doubtful if a true deflation today would be any less unpopular.

\footnotetext{
${ }^{13}$ Friedman and Schwartz ( 1963 ; 41-2) compare the U.S. experience of the 1870 s when money growth exceeded the growth of the labor force but not the growth of real output so that nominal wages were rising, with the 1880s when money growth was less than the growth of the labor force and of real growth and money wages declined. They then relate these facts to the increase in labor unrest and agitation over the monetary standard.
} 
Table 1: Test of Parameter Equality across Countries

\begin{tabular}{c|cc} 
& Statistic & p-value \\
\hline Full Sample (1880-1913) & 39.27 & 0.33 \\
Deflationary Sample (1880-1896) & 35.75 & 0.48 \\
Gold Coefficients (Gold) & 9.83 & 0.63
\end{tabular}

Table 2: Chow Test of Slope Parameter Stability between 1880-1896 and 1897-1913

\begin{tabular}{c|cc} 
& Statistic & p-value \\
\hline United States & 21.18 & 0.270 \\
United Kingdom & 19.92 & 0.337 \\
Germany & 23.16 & 0.185 \\
Panel(Full Sample) & 15.23 & 0.646
\end{tabular}

Table 3: Test of Over-identifying Restrictions

\begin{tabular}{c|cccccc} 
& \multicolumn{2}{|c}{ United States } & \multicolumn{2}{c}{ United Kingdom } & \multicolumn{2}{c}{ Germany } \\
& Statistic & p-value & Statistic & p-value & Statistic & p-value \\
\hline Single Equation & 9.19 & 0.003 & 3.53 & 0.061 & 5.18 & 0.025 \\
Panel (Full Sample) & 33.66 & 0.000 & 14.07 & 0.000 & 0.192 & 0.661 \\
Panel (Deflation Sample) & 26.28 & 0.000 & 2.97 & 0.085 & 0.057 & 0.811
\end{tabular}

Table 4: Tests of Exogeneity of Gold

\begin{tabular}{c|cccccc} 
& \multicolumn{2}{|c}{ United States } & \multicolumn{2}{c}{ United Kingdom } & \multicolumn{2}{c}{ Germany } \\
Dependent variable & Statistic & p-value & Statistic & p-value & Statistic & p-value \\
\hline Price & 0.105 & 0.75 & 0.301 & 0.58 & 0.706 & 0.40 \\
Output & 0.108 & 0.74 & 0.018 & 0.89 & 0.483 & 0.49 \\
Money & 0.002 & 0.97 & 0.001 & 0.99 & 0.003 & 0.95
\end{tabular}




\section{Figure 1: Data for Core Countries}
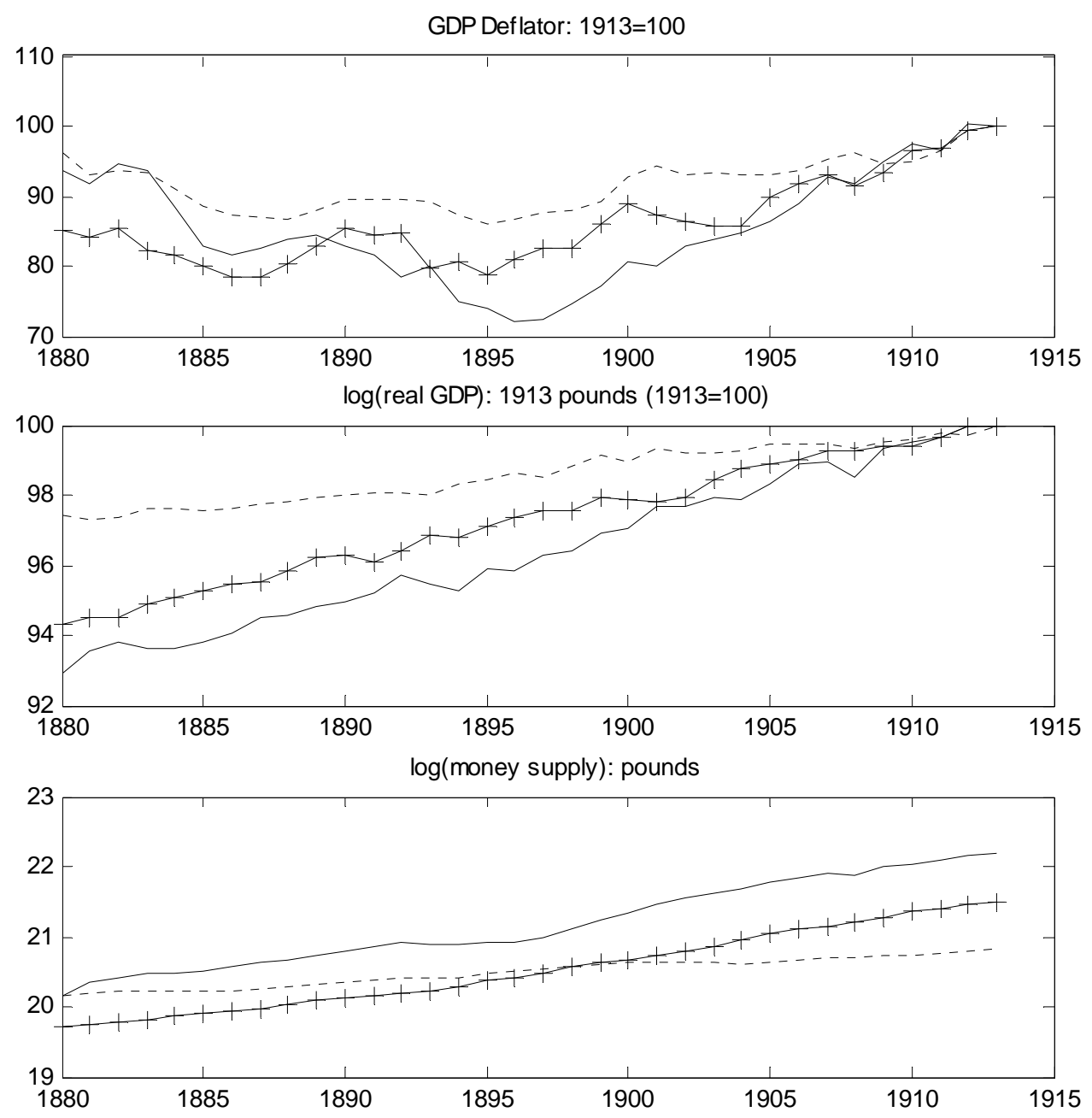

\begin{tabular}{|l}
- United States \\
--- United Kingdom \\
+ Germany
\end{tabular}


Figure 2: Gold Production: 1873-1913

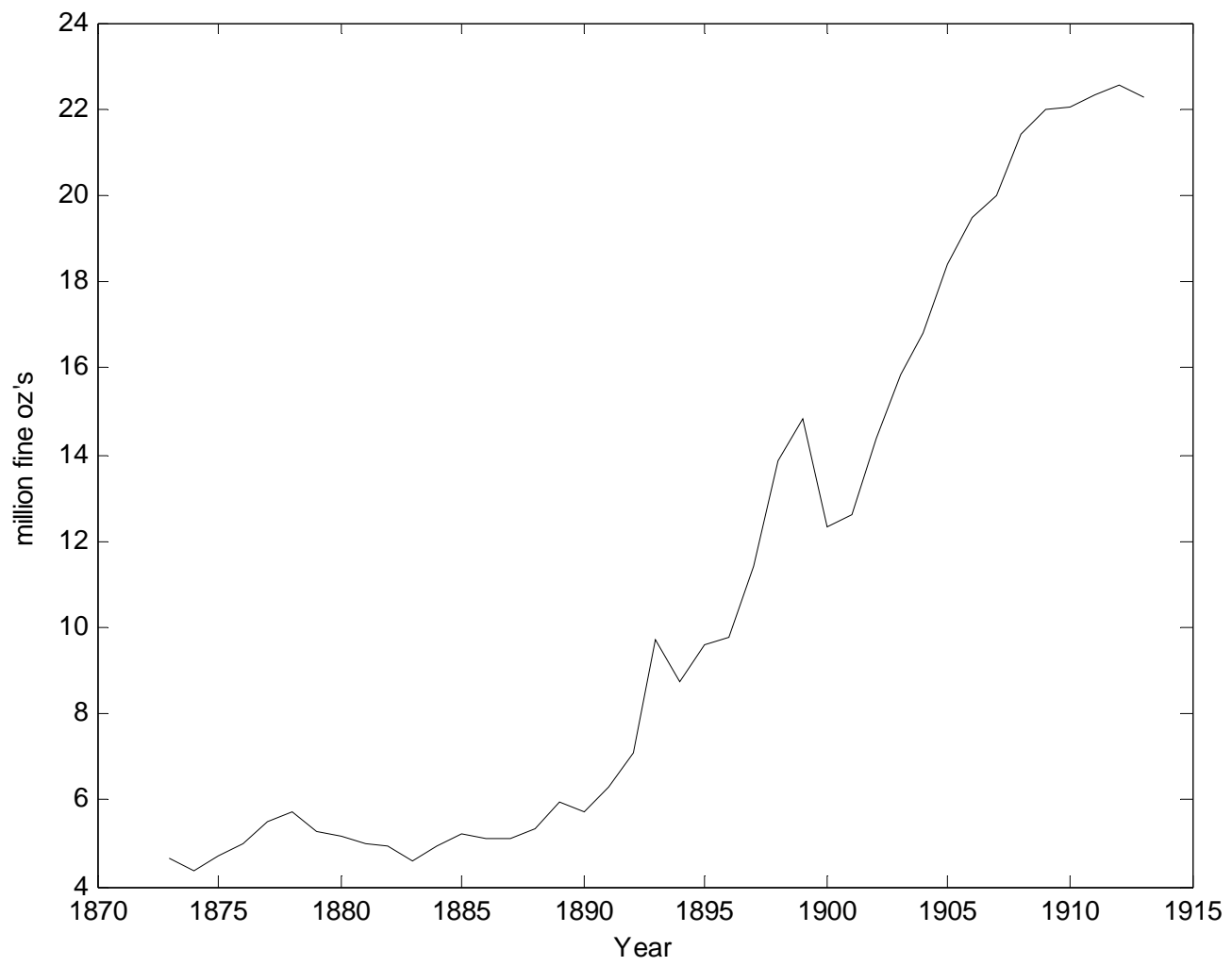




\section{Figure $3^{14}$ : Structural Impulse Response Functions: United States (Full Sample)}
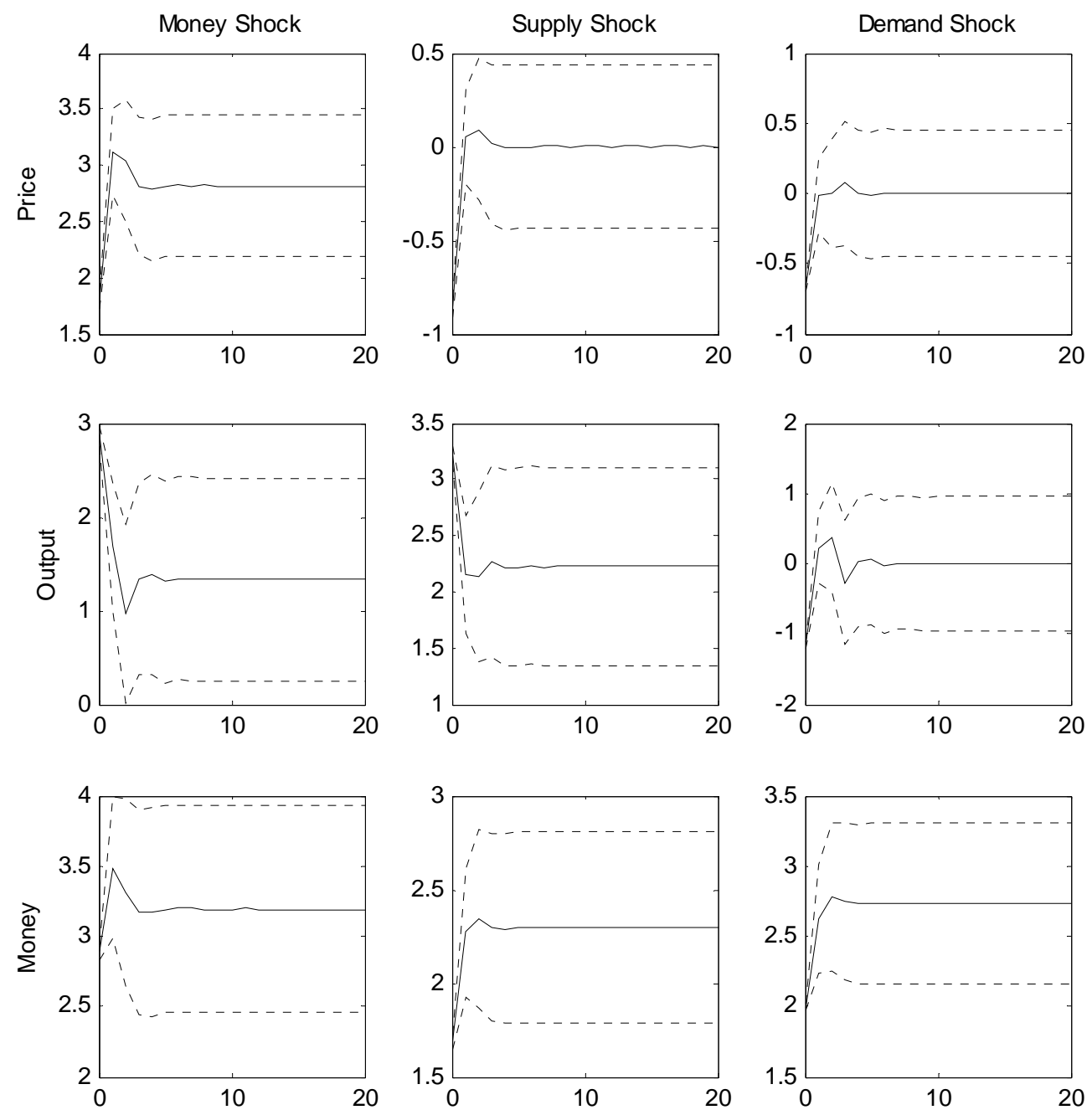

\footnotetext{
${ }^{14}$ The $y$-axis for all impulse response functions are measured in percentage points.
} 
Figure 4: Structural Impulse Response Functions: United Kingdom (Full Sample)
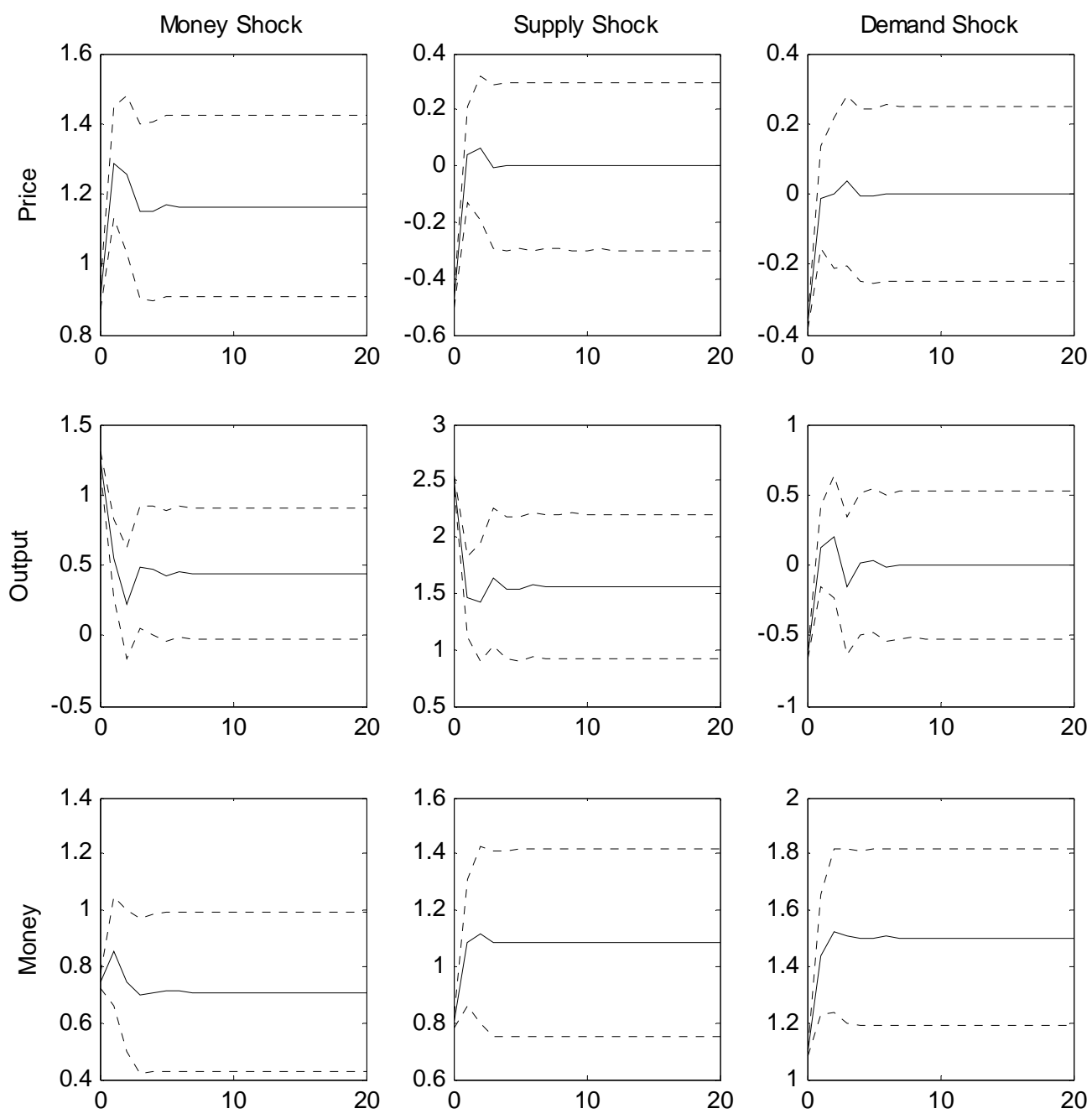
Figure 5: Structural Impulse Response Functions: Germany (Full Sample)
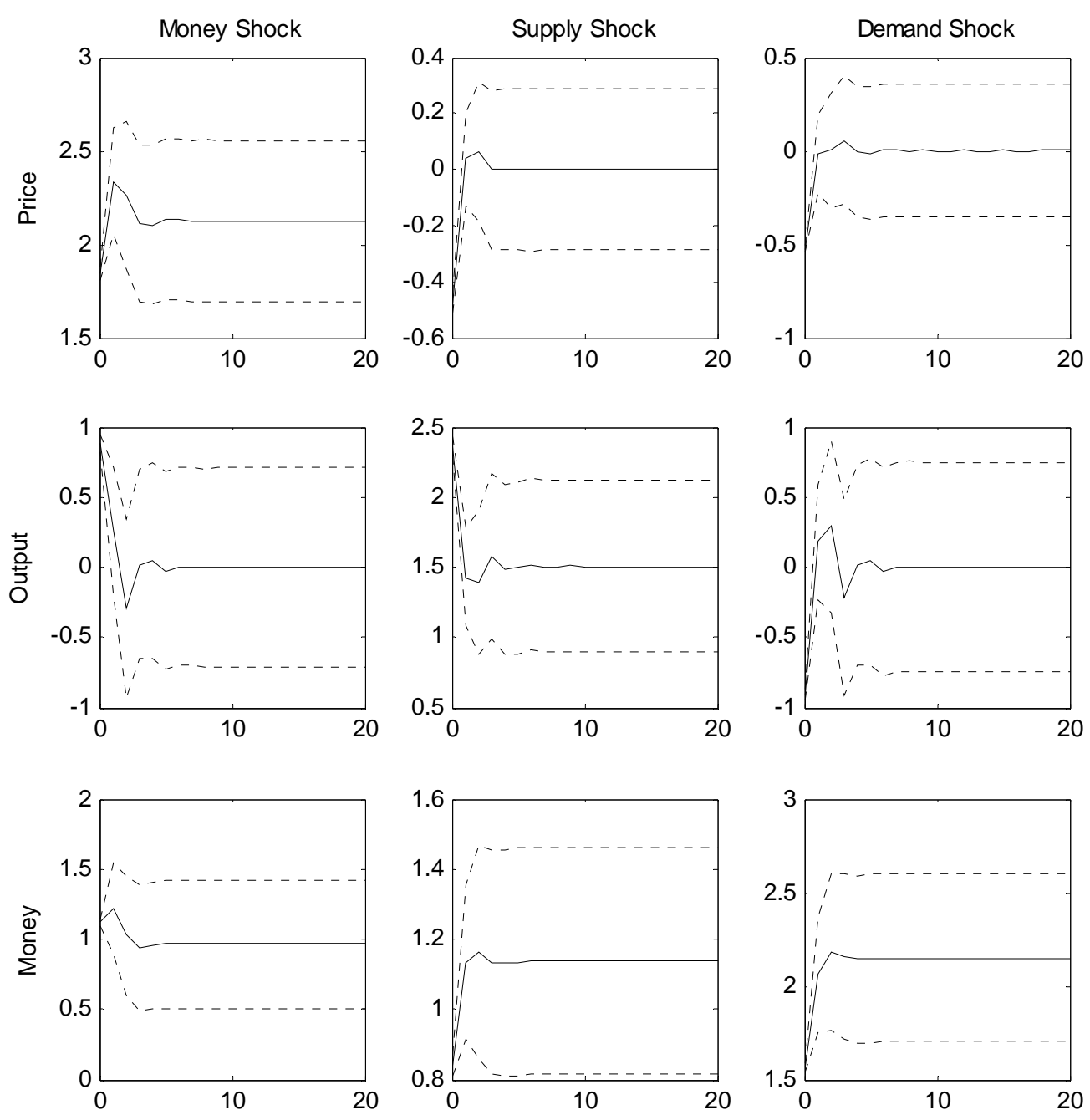
Figure 6a: Historical Decomposition of Prices: US (Full Sample)
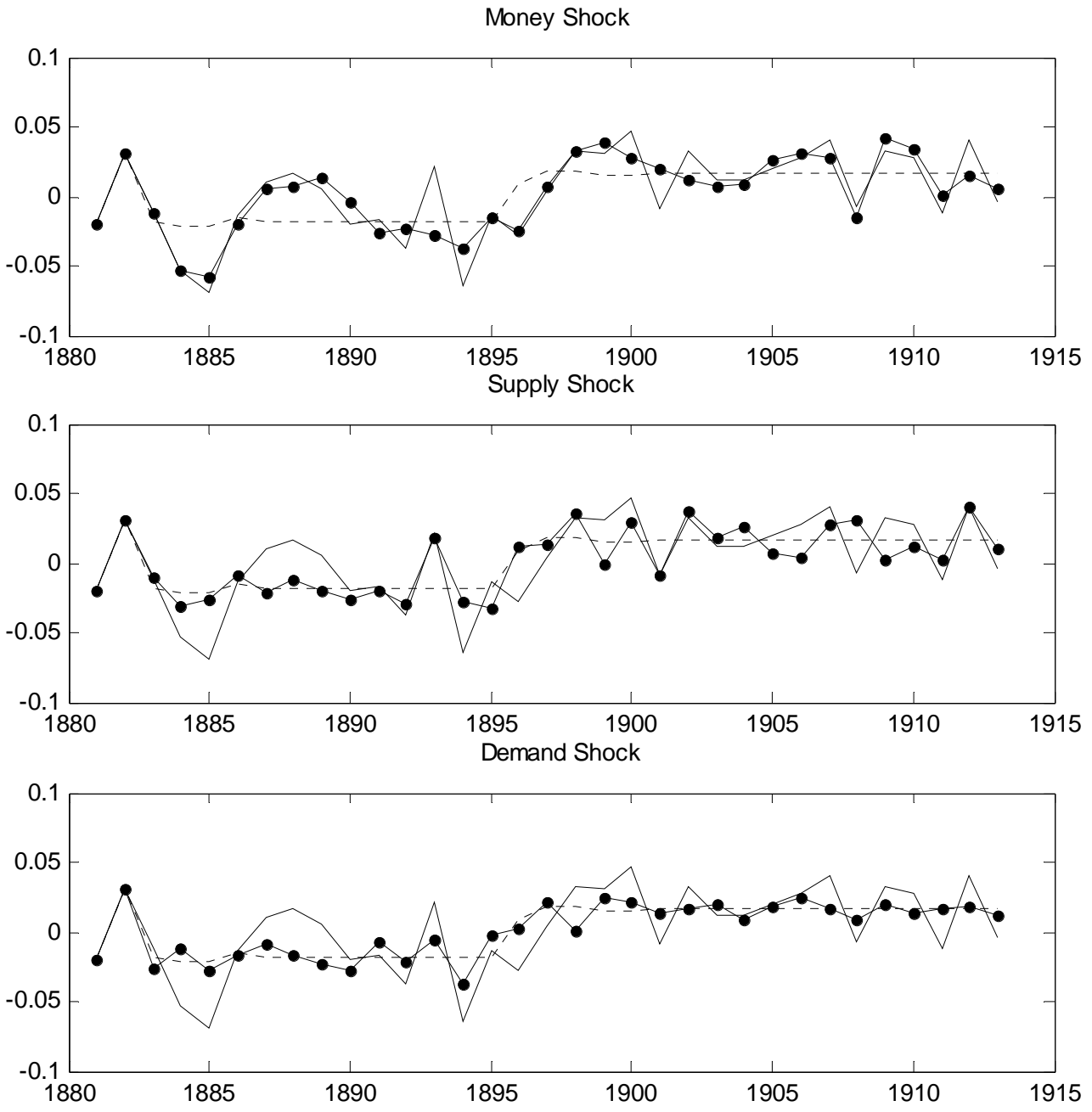

_ Actual Series
$\ldots-$ Baseline
$\ldots$ Baseline+Shock


Figure 6b: Historical Decomposition of Output: US (Full Sample)
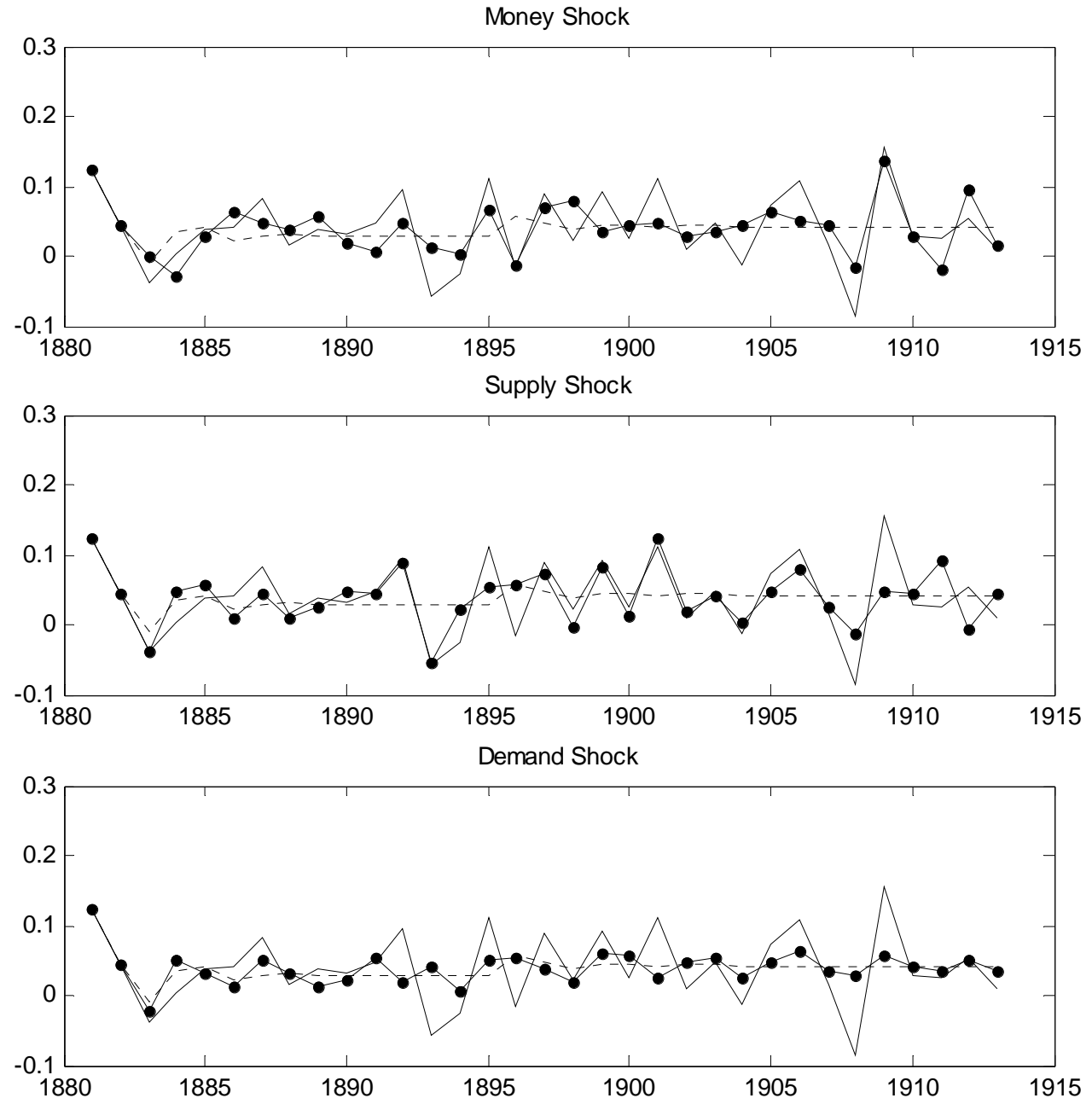

Actual Series

- . Baseline

- Baseline+Shock 
Figure 7a: Historical Decomposition of Prices: UK (Full Sample)
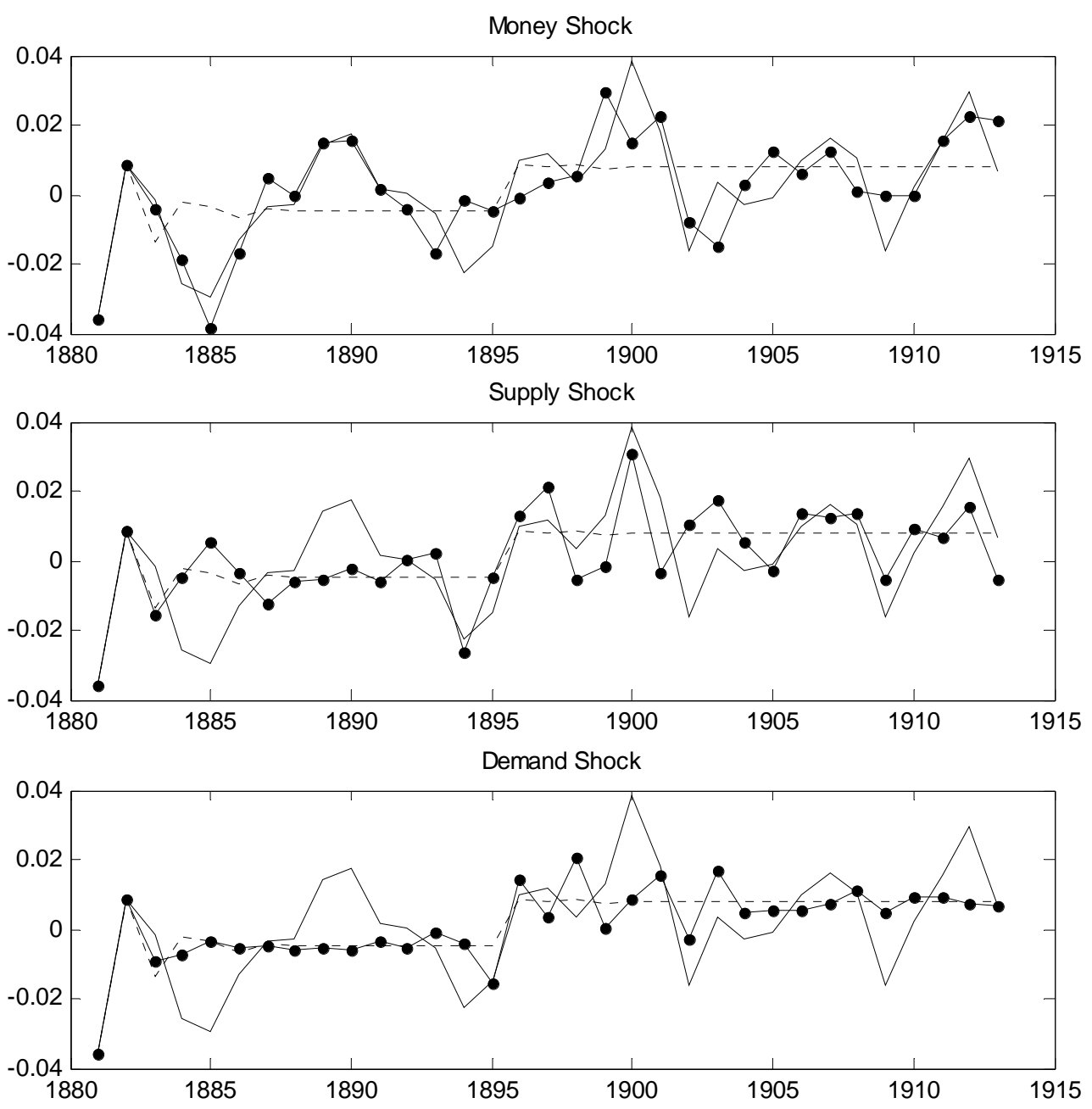

_ Actual Series
$\ldots-$ Baseline
- Baseline+Shock


Figure 7b: Historical Decomposition of Output: UK (Full Sample)
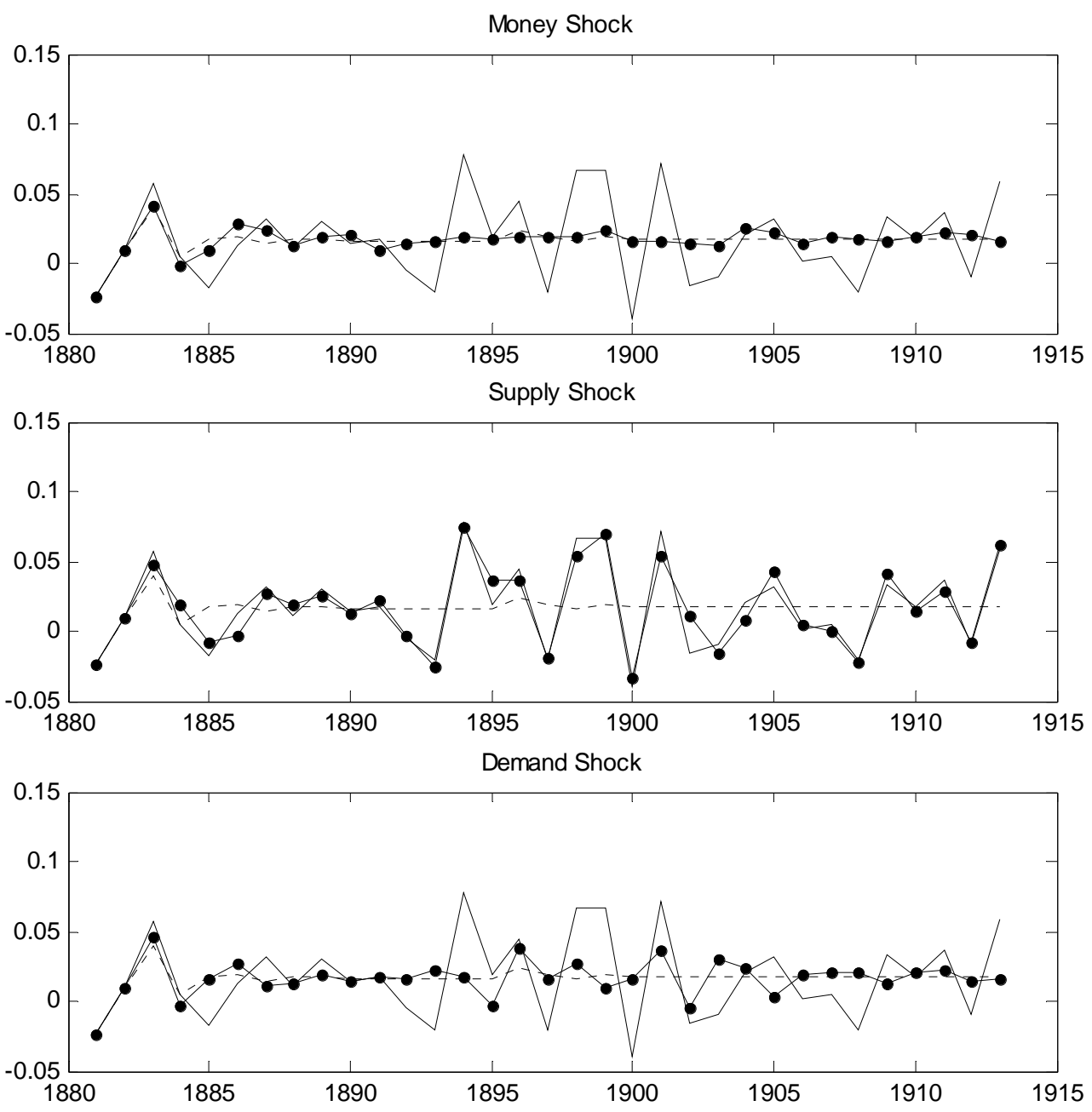

- Actual Series
--- Baseline
- Baseline+Shock


Figure 8a: Historical Decomposition of Prices: Germany (Full Sample)
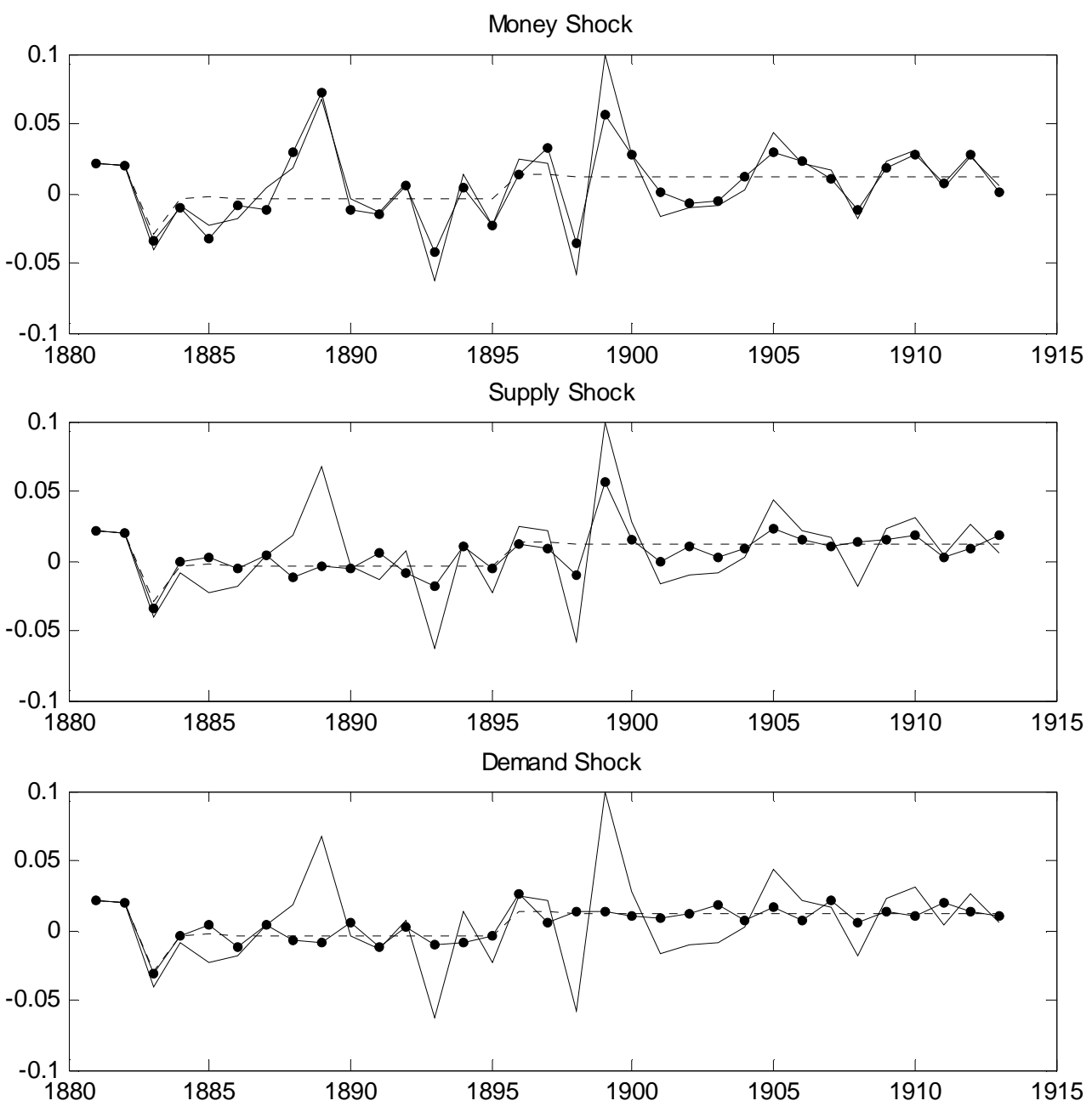

- Actual Series
- - Baseline
- Baseline+Shock


Figure 8b: Historical Decomposition of Output: Germany (Full Sample)
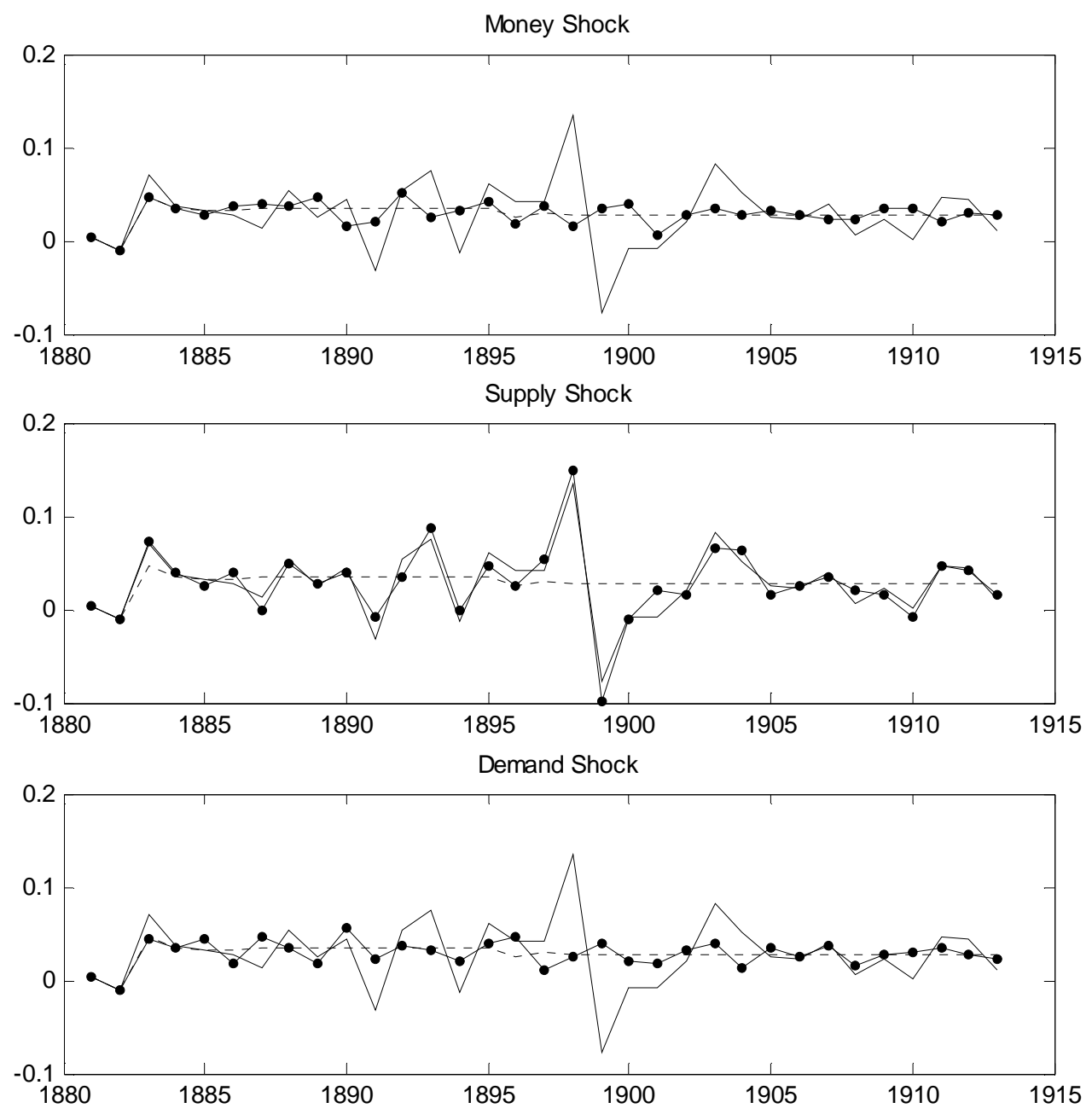
Figure 9: Estimated Structural Shocks from the Panel (Full Sample)
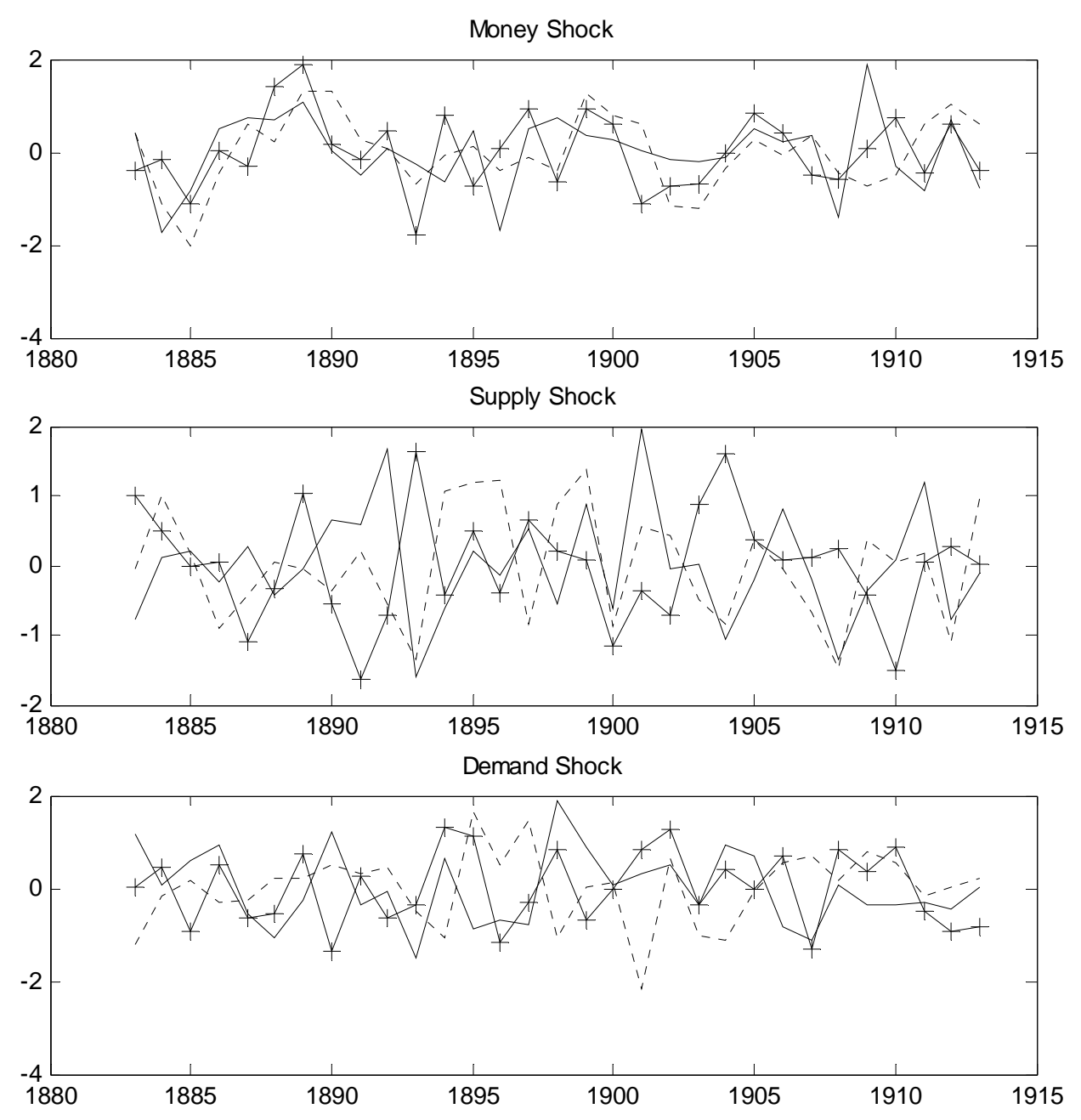

\begin{tabular}{|ll|}
\hline-- & United States \\
-- & United Kingdom \\
+ & Germany \\
\hline
\end{tabular}


Figure 10: Structural Impulse Response Function: US (Deflationary Sample)
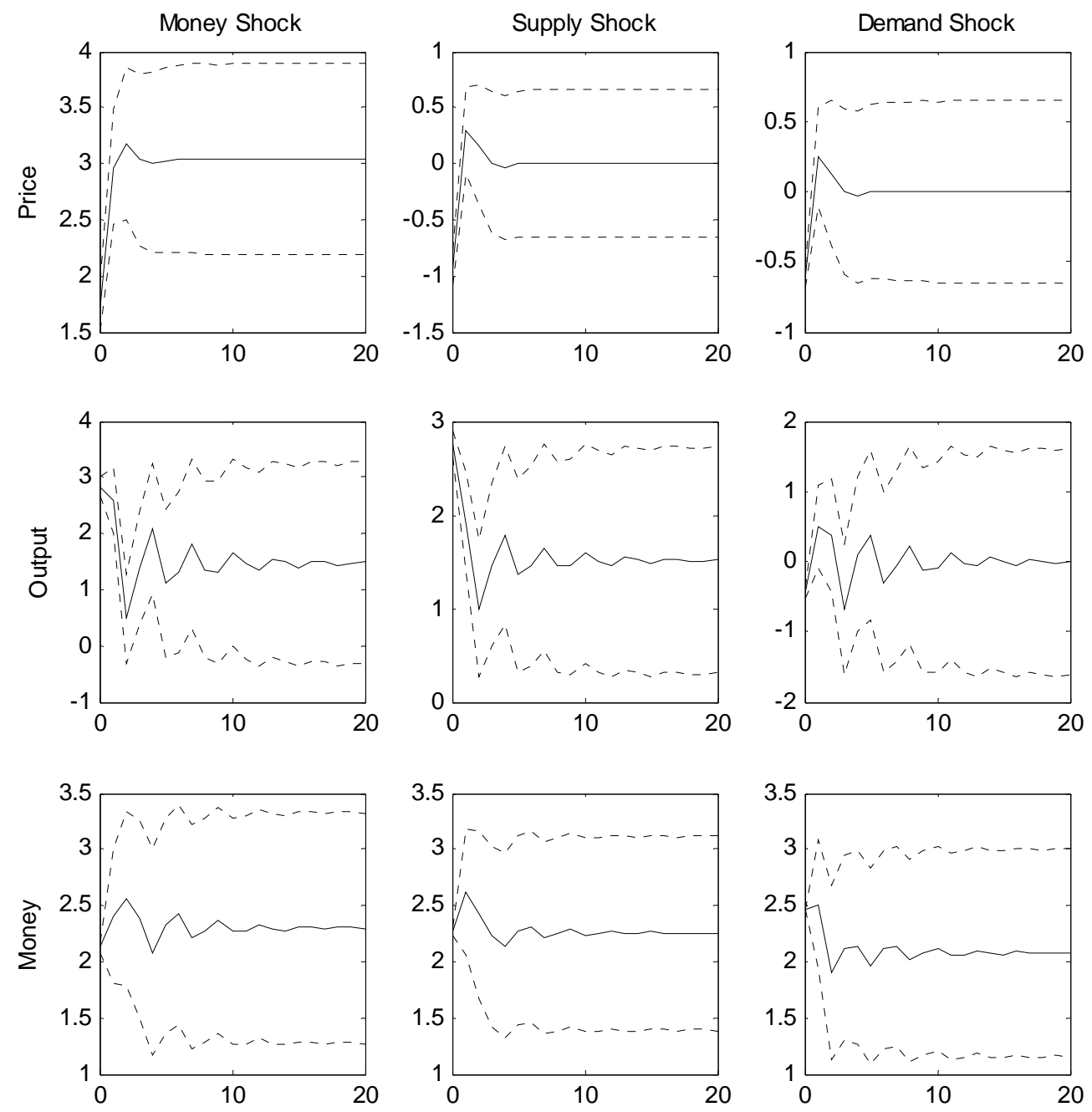
Figure 11: Structural Impulse Response Function: UK (Deflationary Sample)
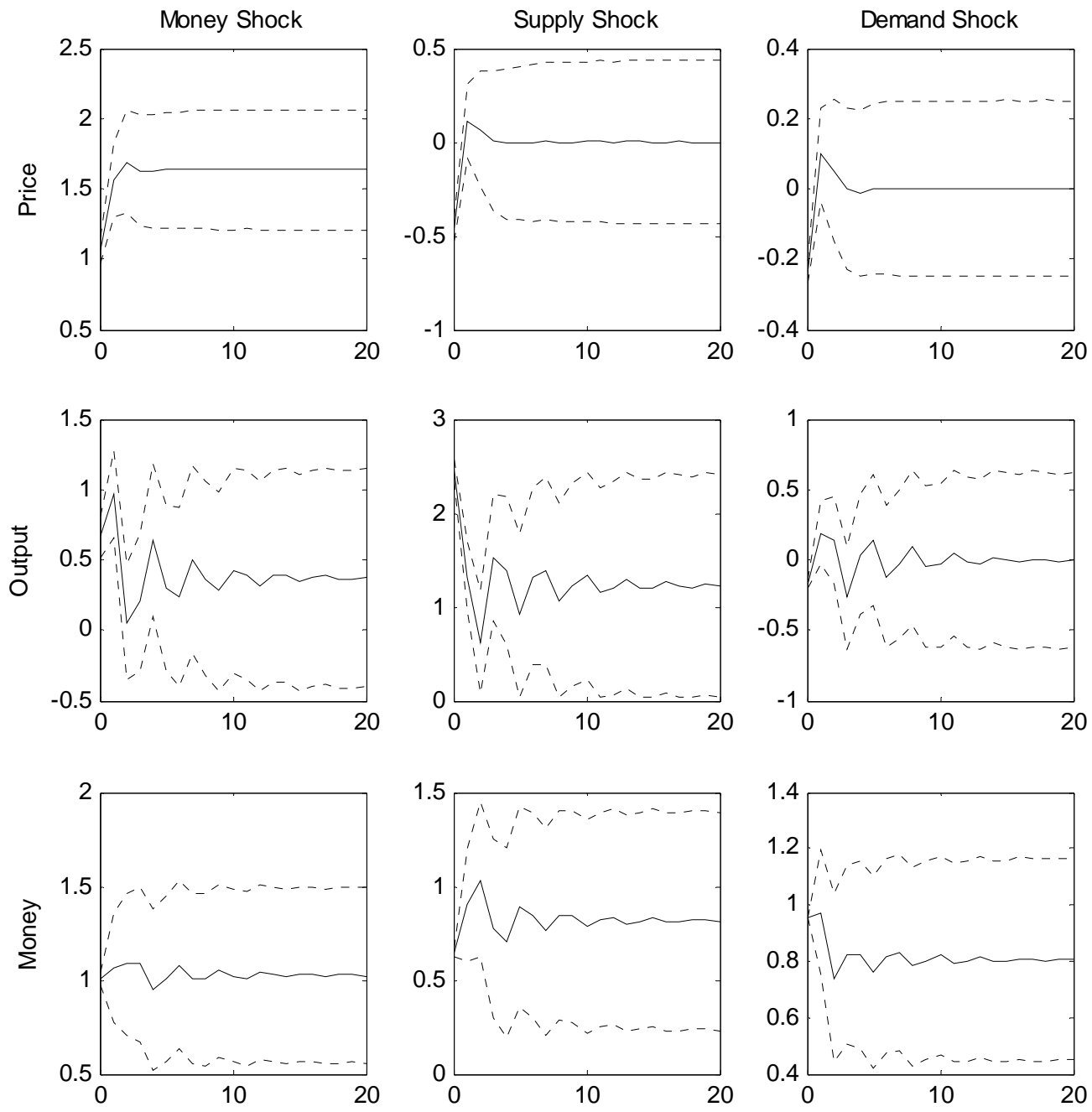
Figure 12: Structural Impulse Response Function: Germany (Deflationary Sample)
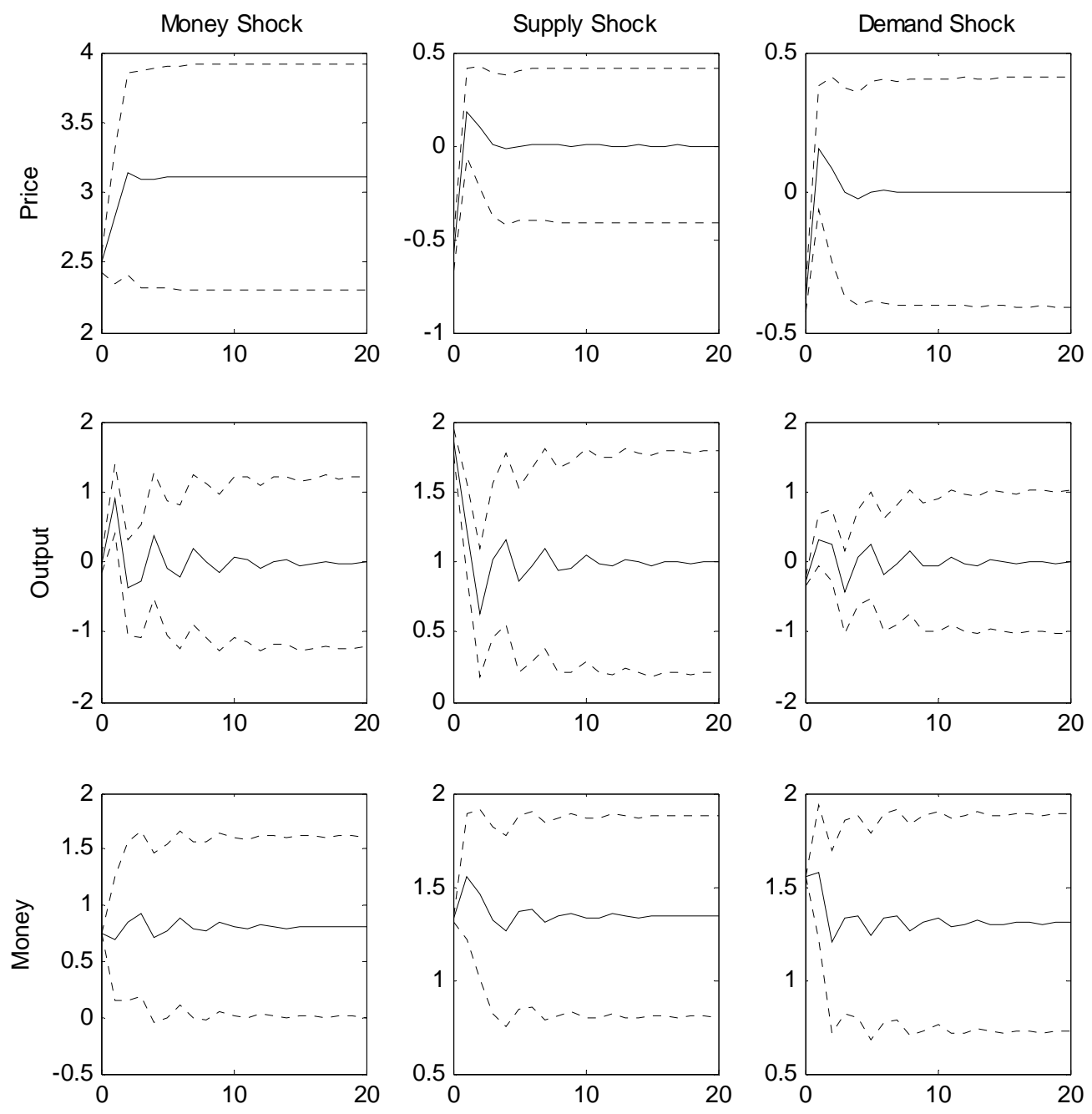
Figure 13a:Historical Decomposition of Prices: US (Deflationary Sample)
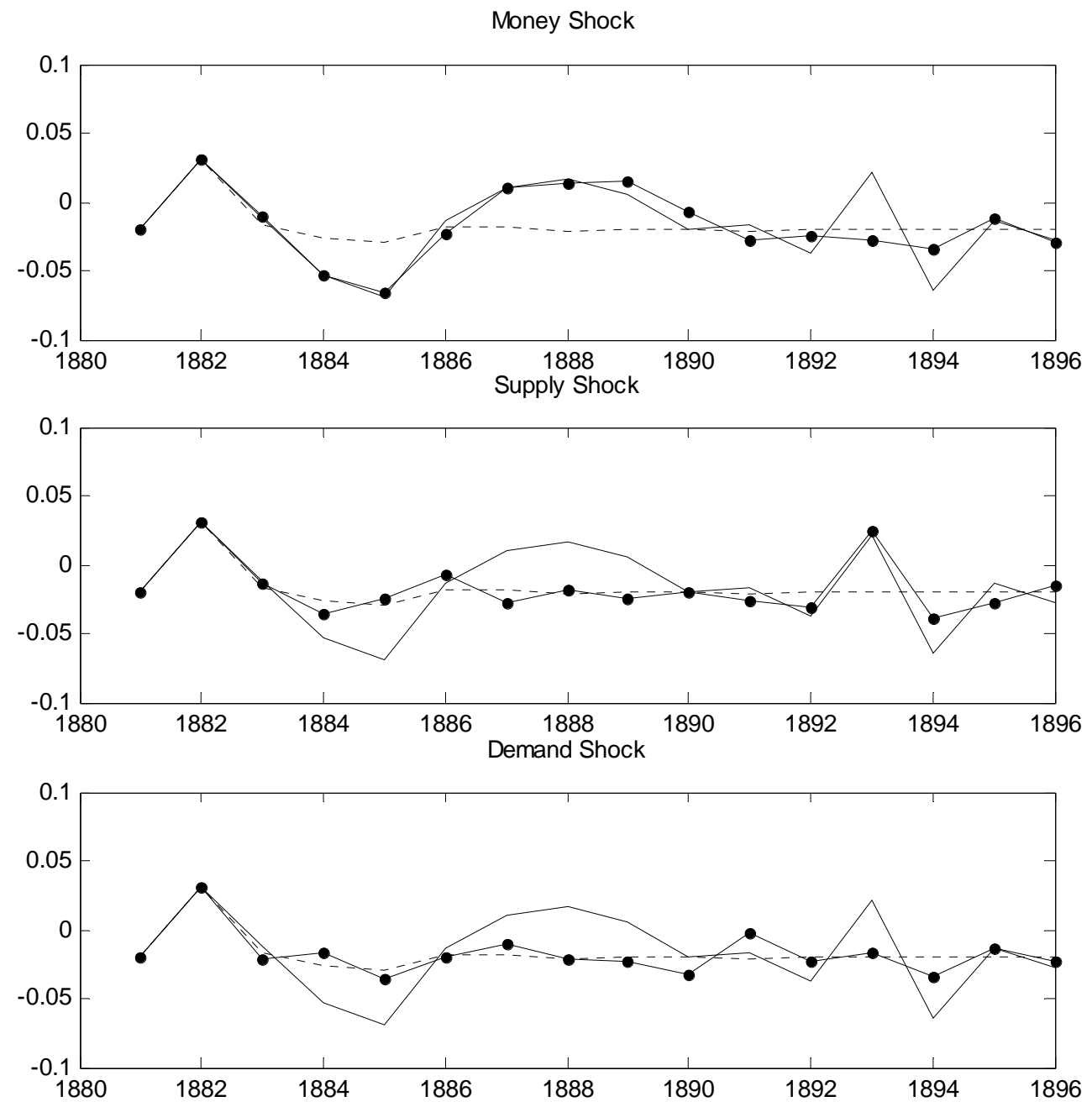

\begin{tabular}{ll}
\hline- Actual Series \\
--- Baseline \\
- Baseline+Shock
\end{tabular}


Figure 13b: Historical Decomposition of Output: US (Deflationary Sample)
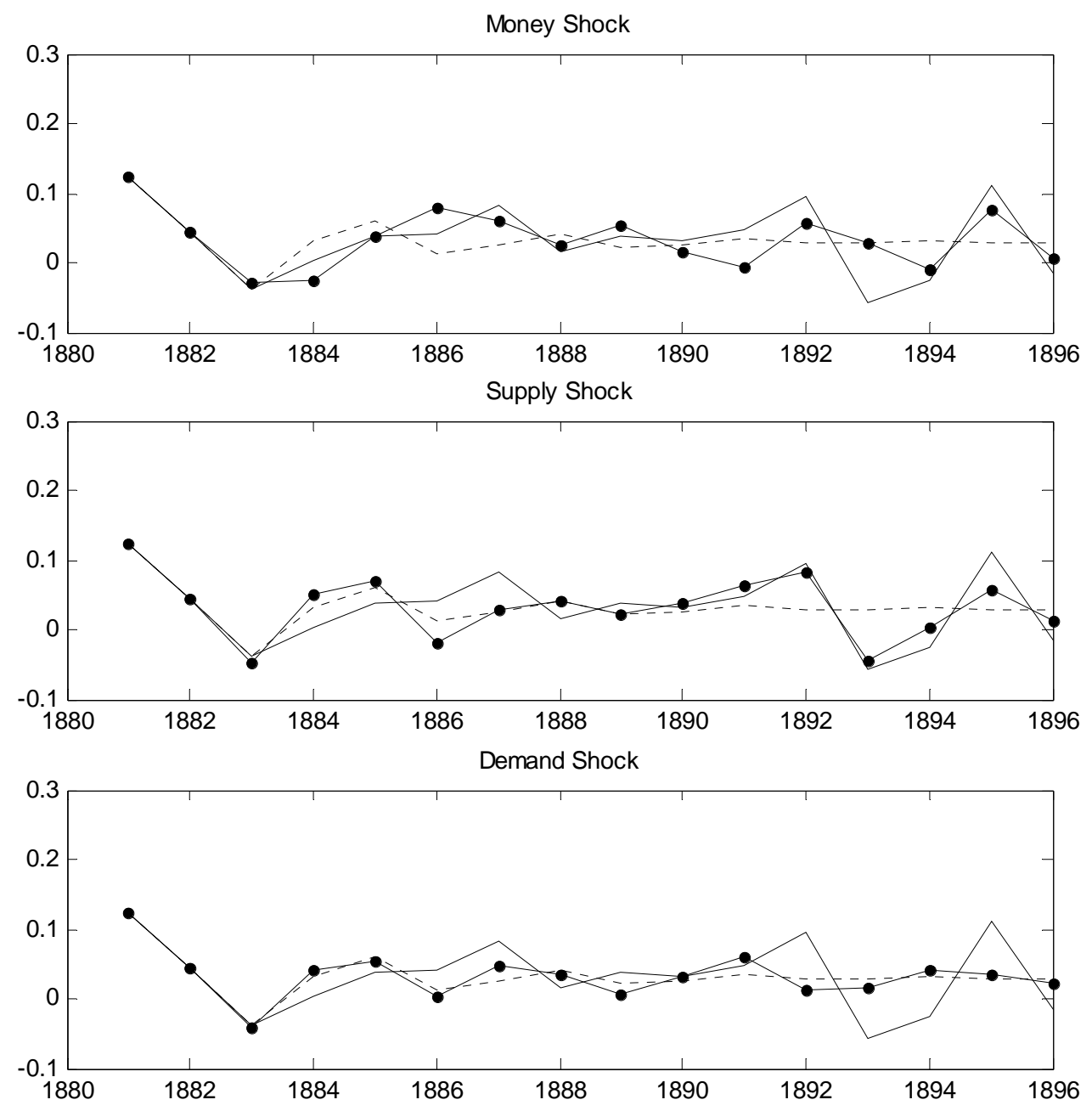

_ Actual Series
-- Baseline
- Baseline+Shock


Figure 14a: Historical Decomposition of Prices: UK (Deflationary Sample)
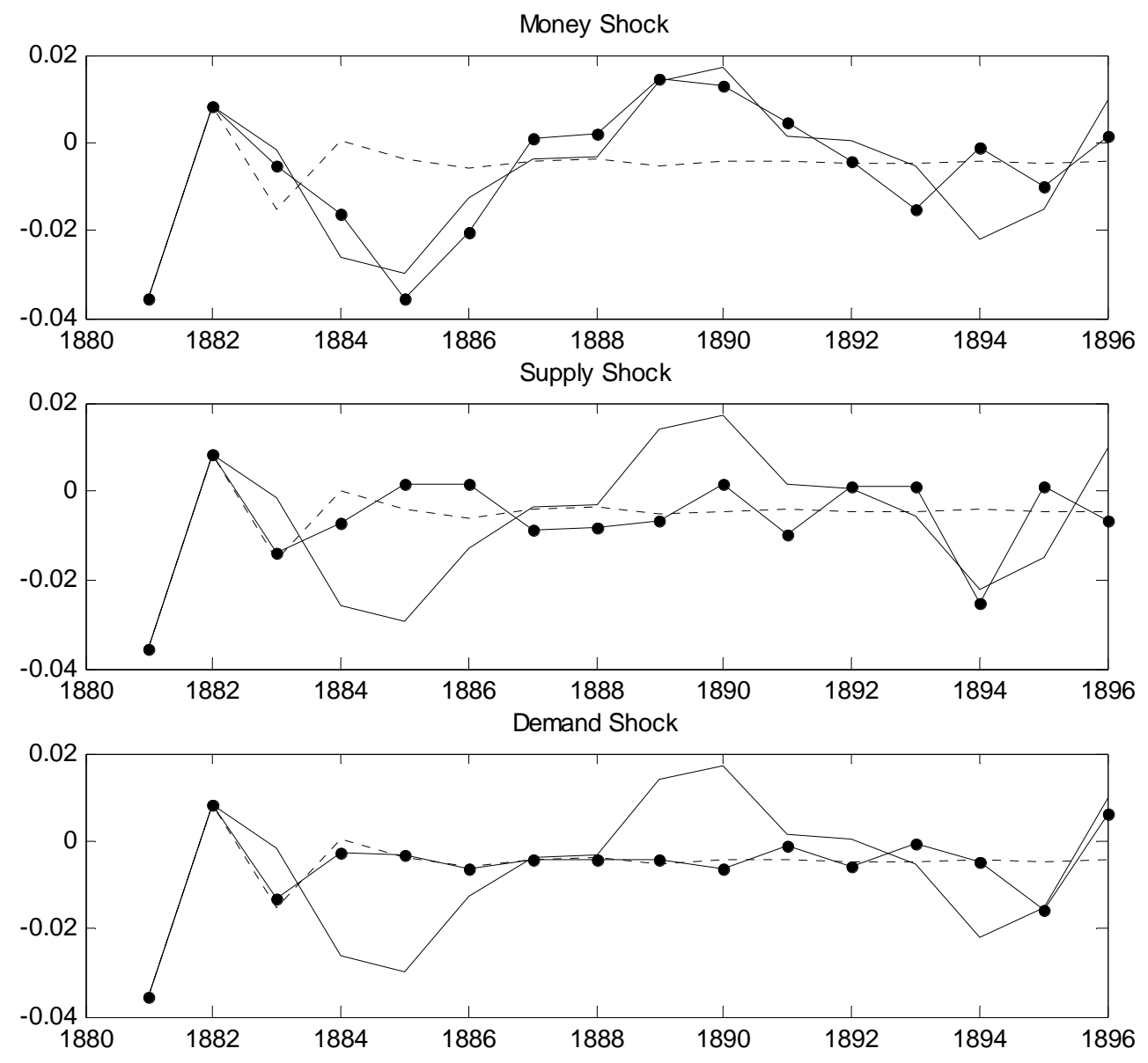

- Actual Series
--- Baseline
- Baseline+Shock 
Figure 14b: Historical Decomposition of Output: UK (Deflationary sample)
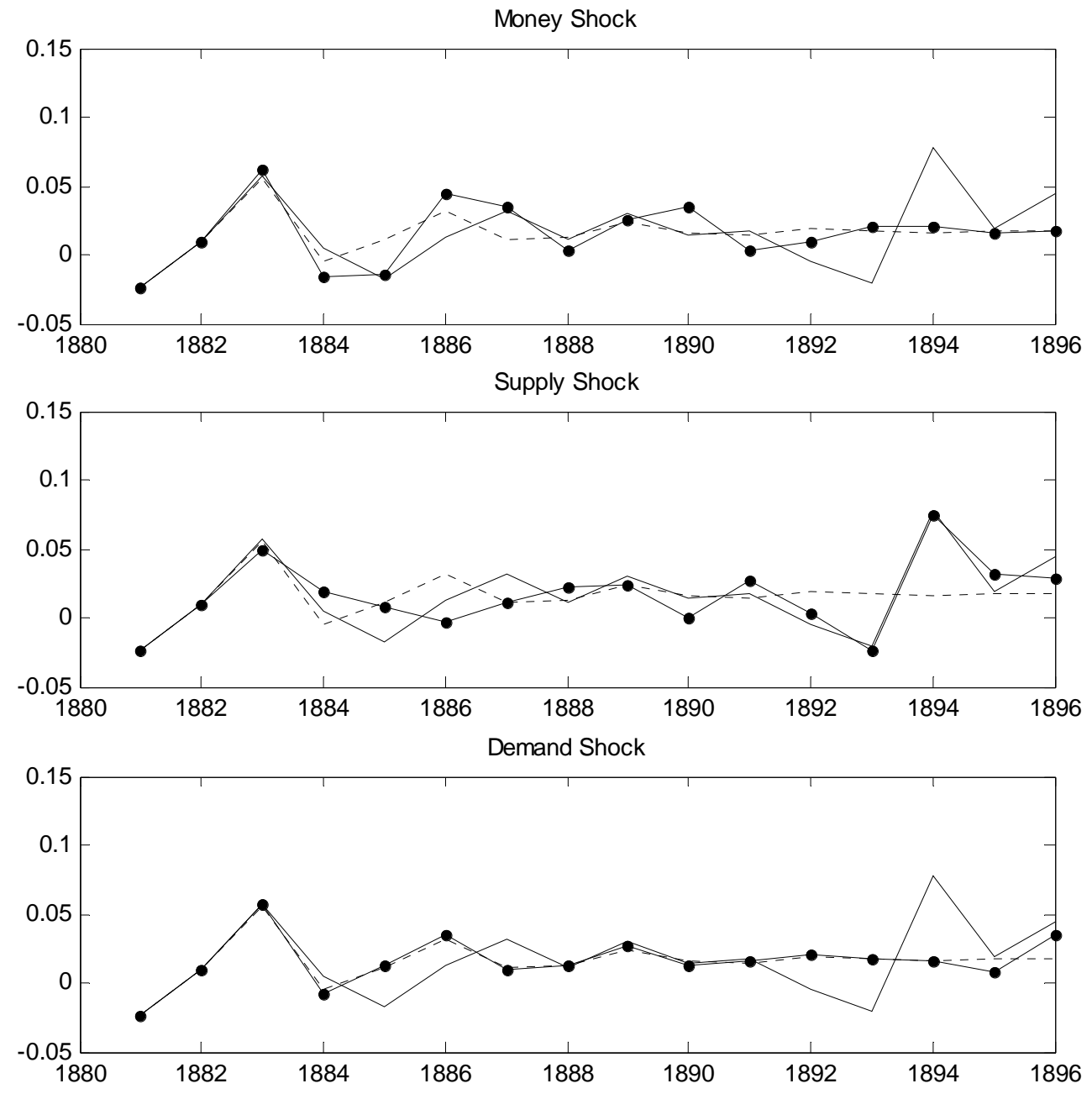

- Actual Series
$-\ldots$ Baseline
- Baseline+Shock


Figure 15a: Historical Decomposition of Prices: GERMANY (Deflationary Sample)
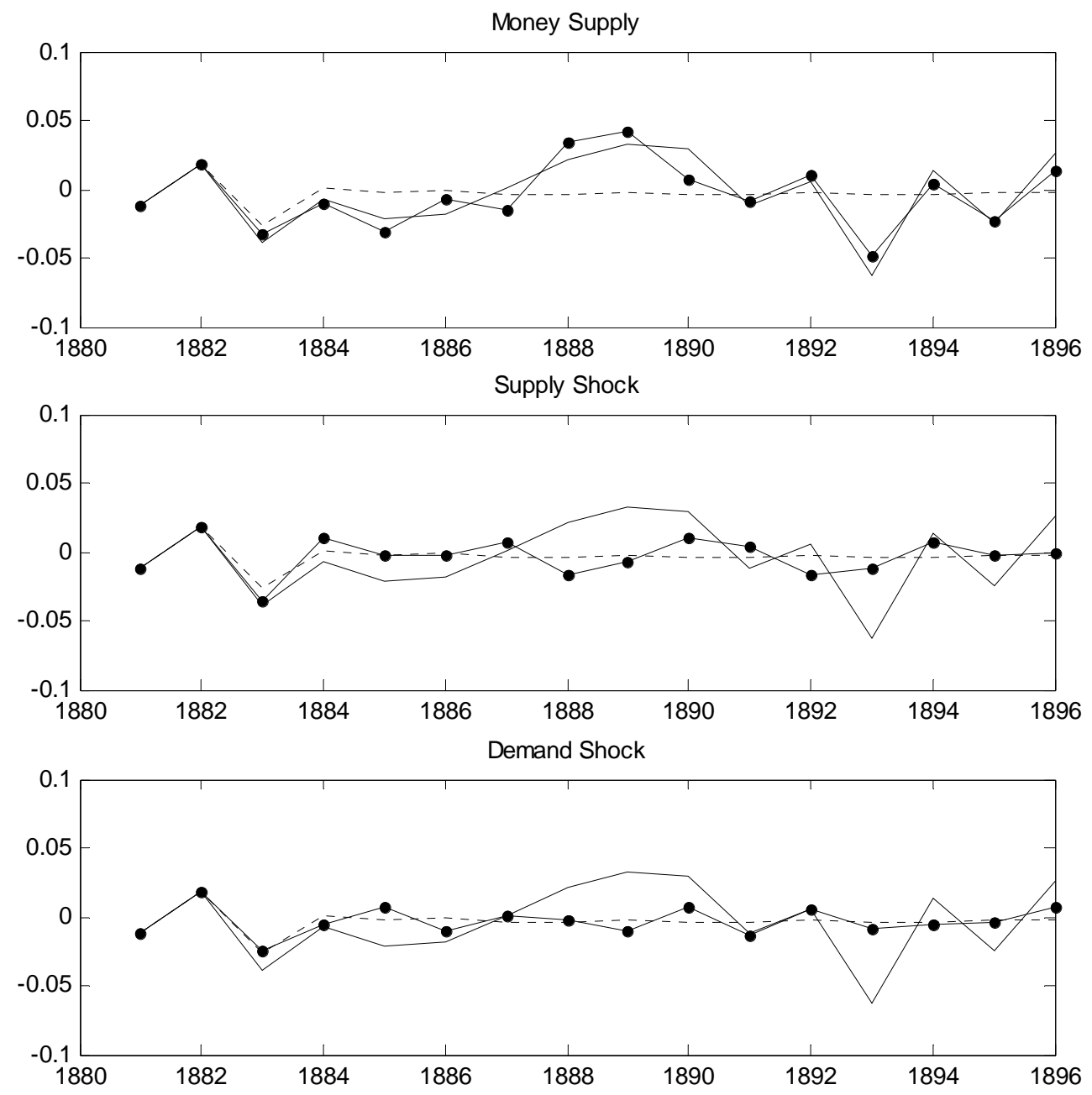
Figure 15b: Historical Decomposition of Output: Germany (Deflationary Sample)
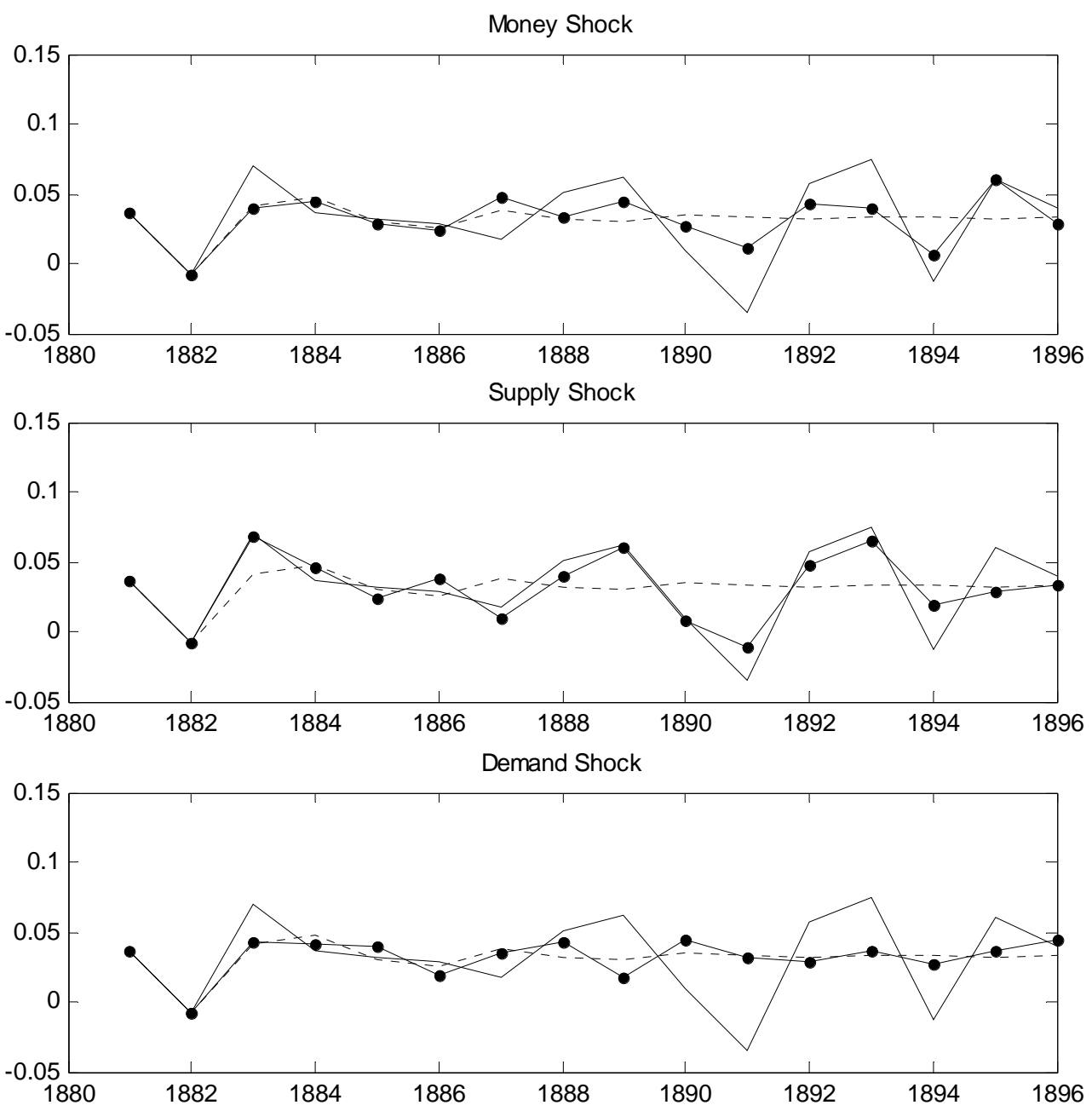

- Actual Series
--- Baseline
- Baseline+Shock


Figure 16: Structural Impulse Response Function: US (Full Sample with Gold)
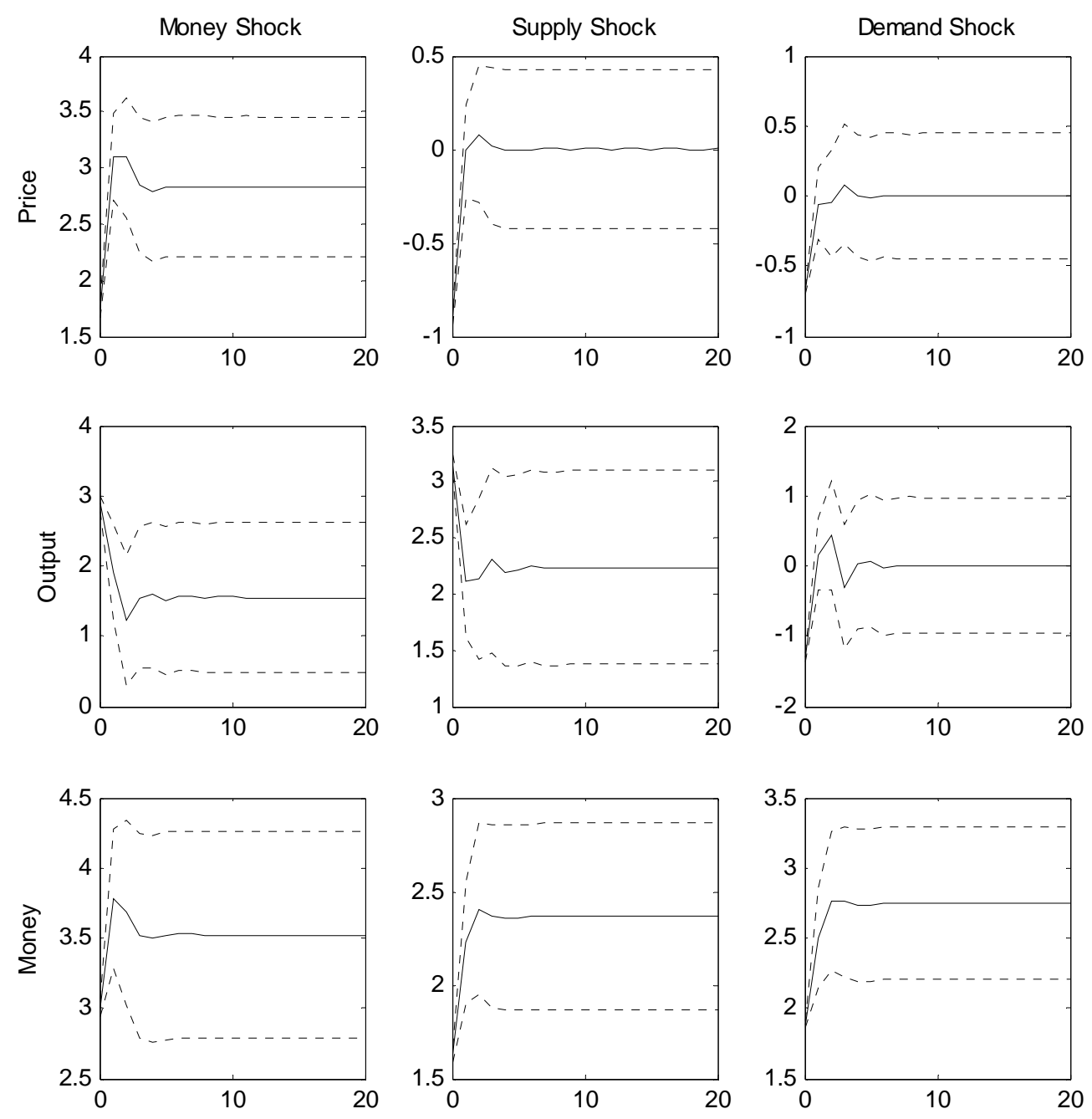
Figure 17: Structural Impulse Response Function: UK (Full Sample with Gold)
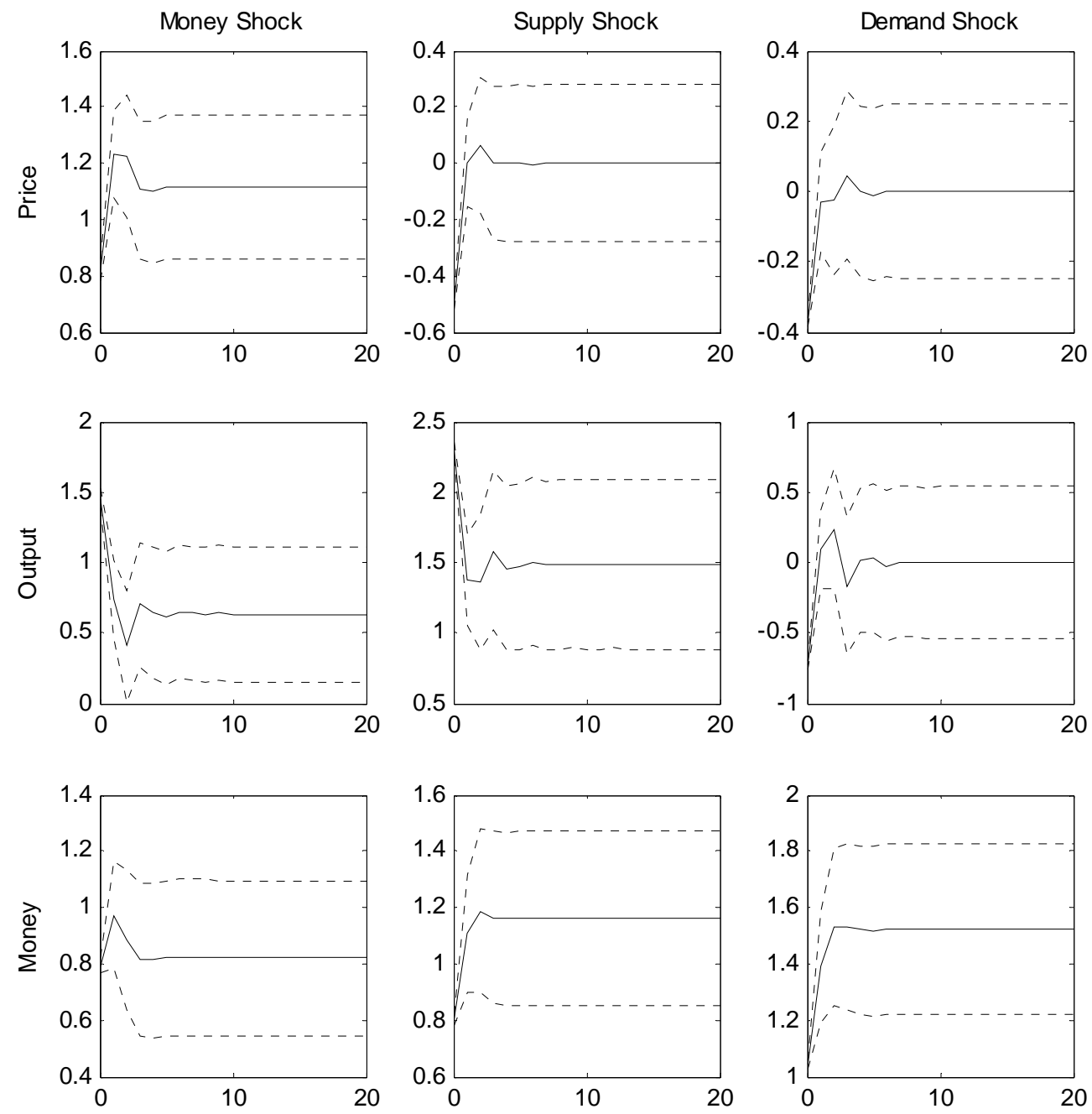
Figure 18: Structural Impulse Response Function: Germany (Full Sample with Gold)
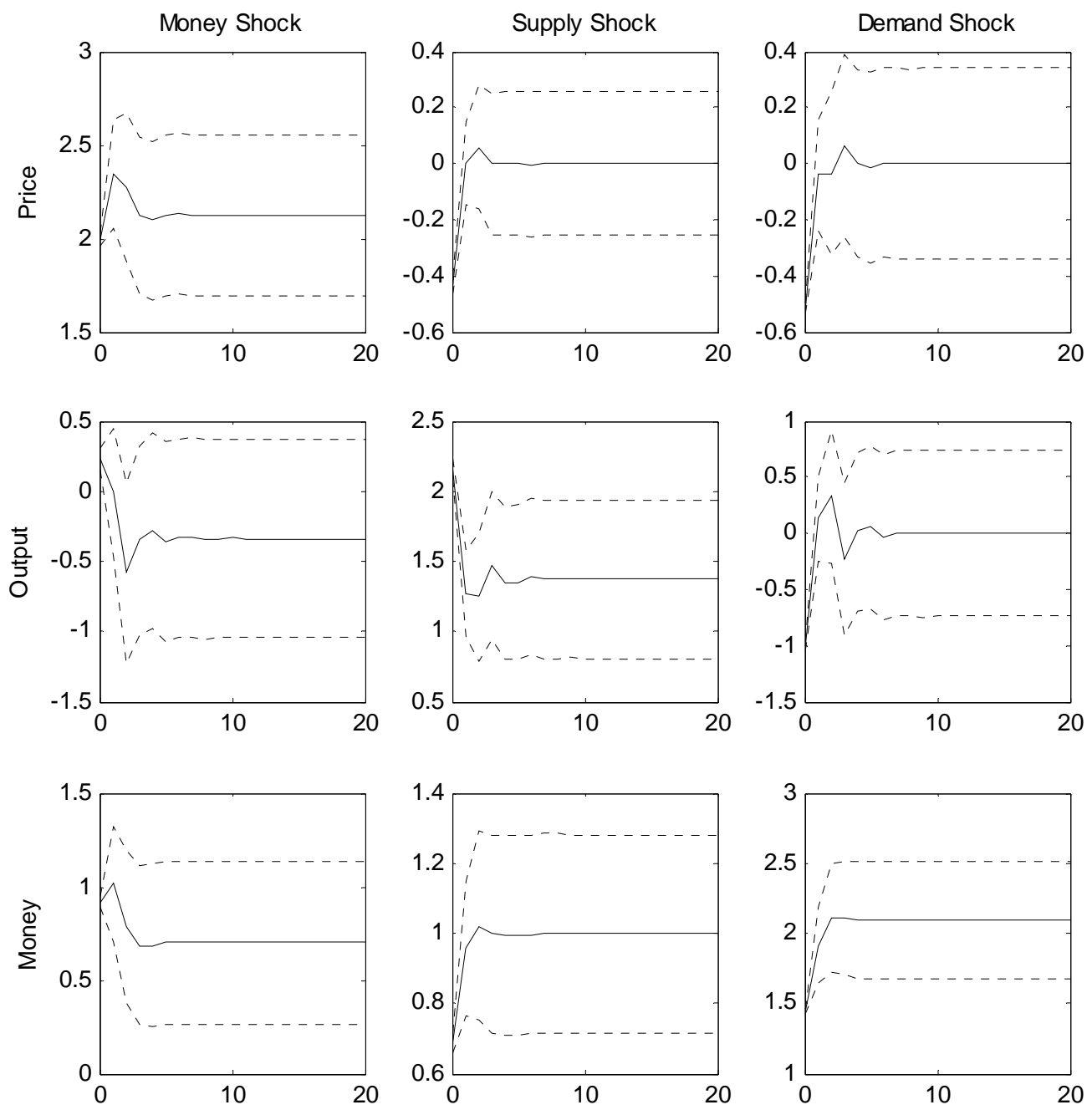
Figure 19: Impulse Response to a 1\% Increase in Gold
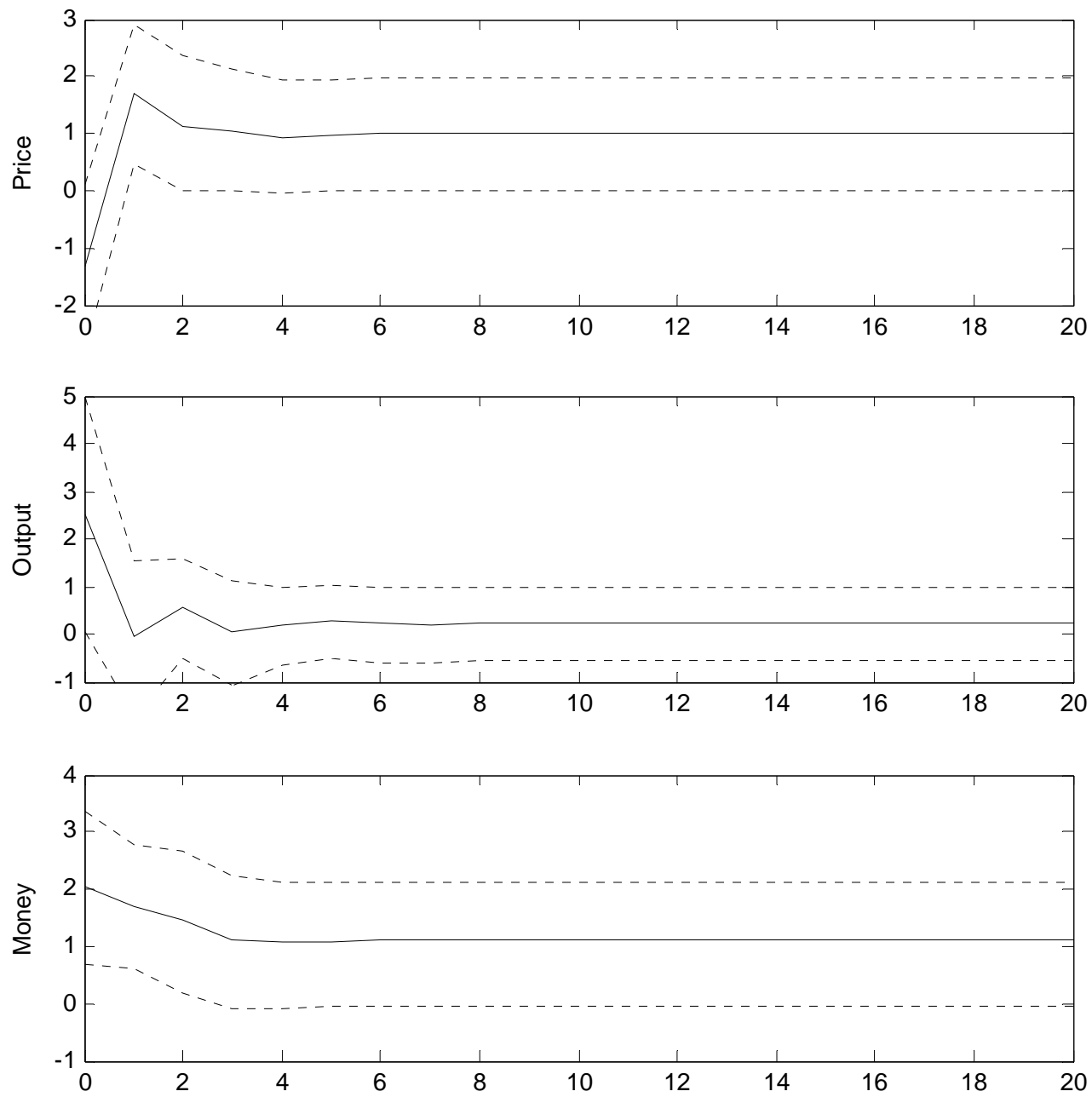
Figure 20a: Historical Decomposition of Price: US (Full Sample with Gold)
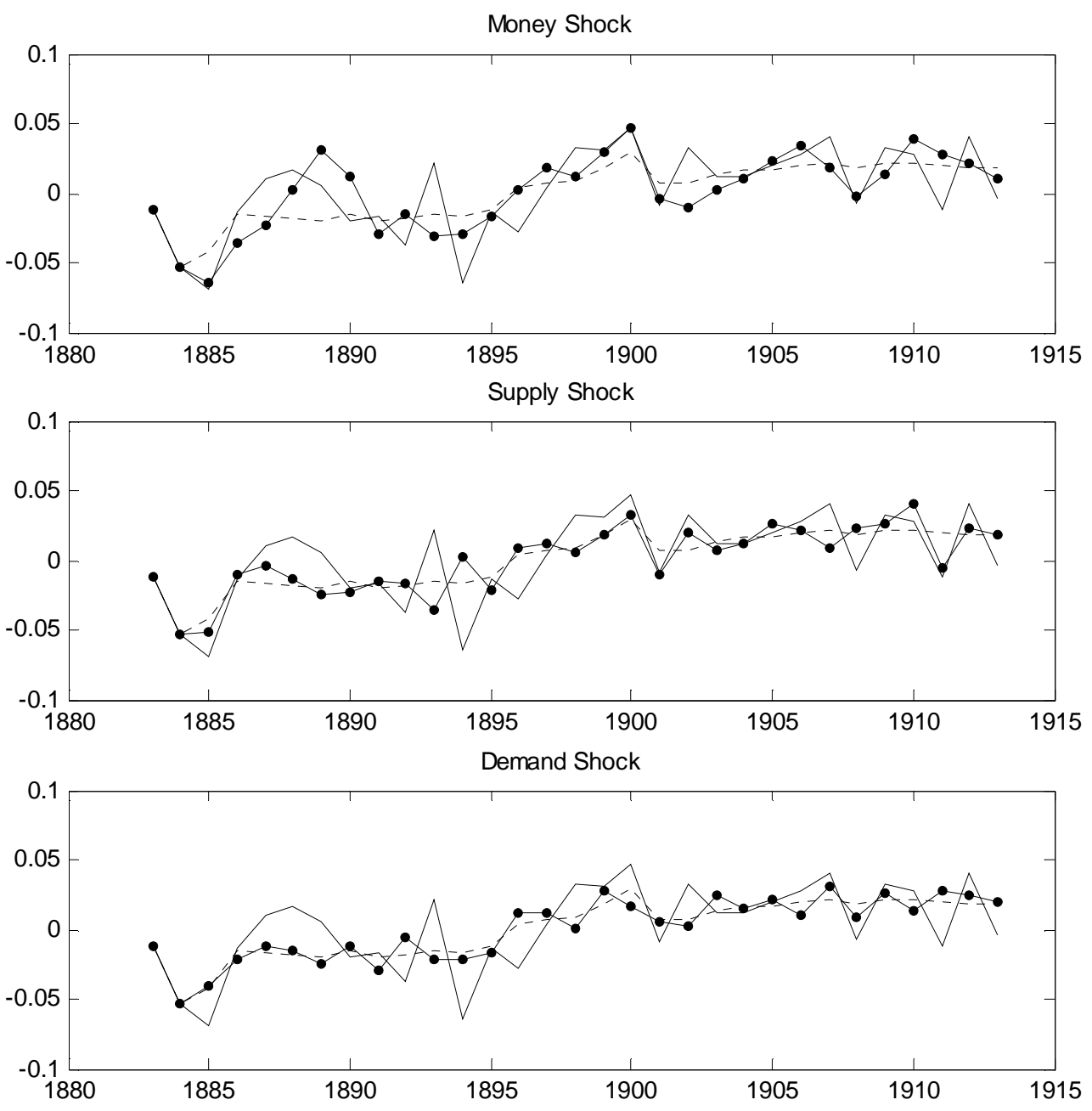

$$
\begin{array}{ll}
- & \text { Actual } \\
--- & \text { Baseline + Gold Shock } \\
- & \text { Baseline+Gold Shock Shock }
\end{array}
$$


Figure 20b: Historical Decomposition of Output: US (Full Sample with Gold)
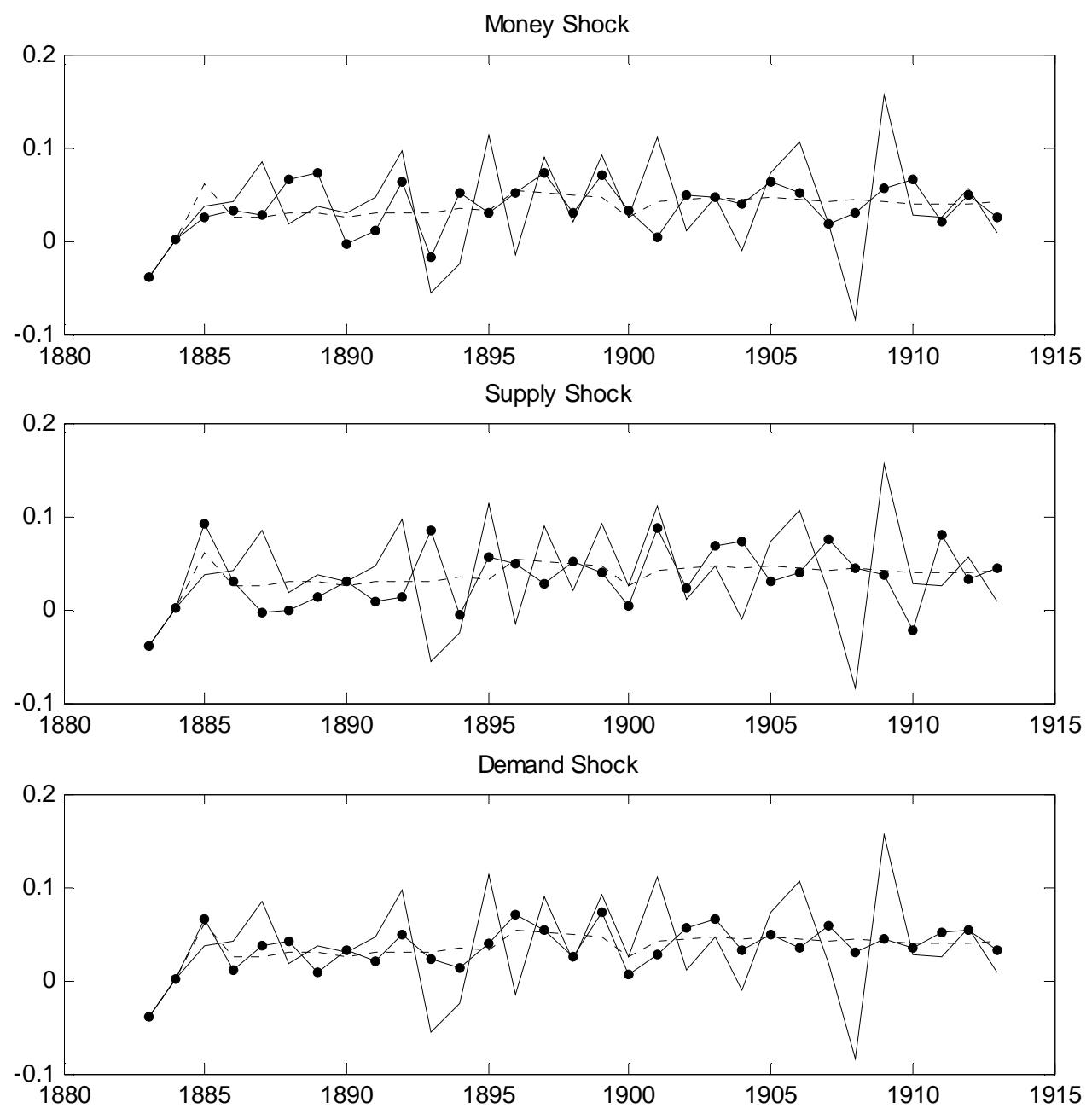

- Actual
- - Baseline + Gold Shock
- Baseline+Gold Shock Shock


Figure 21a: Historical Decomposition of Price: UK (Full Sample with Gold)
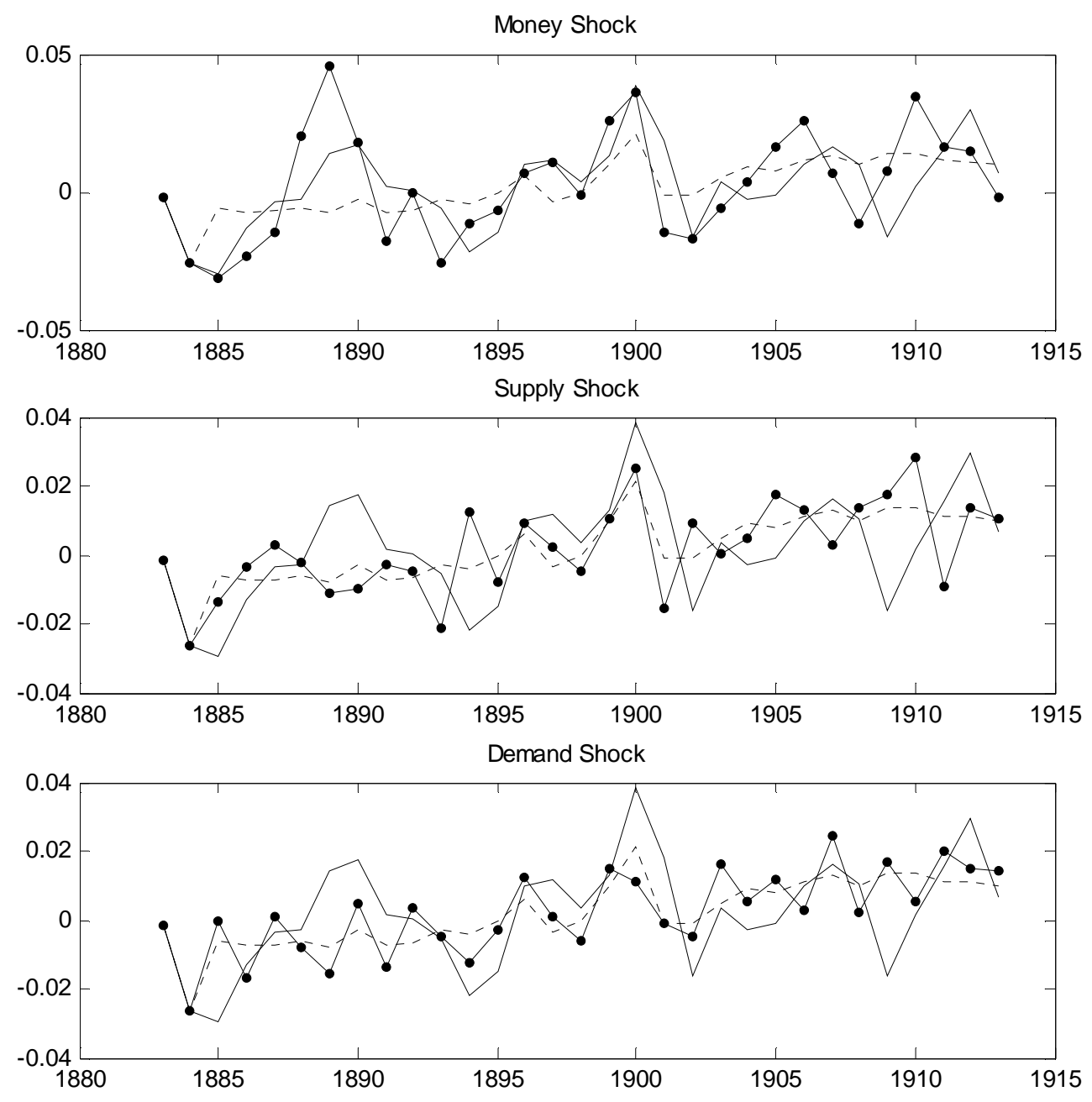

- Actual
- - Baseline + Gold Shock
$\ldots$ Baseline+Gold Shock Shock


Figure 21b: Historical Decomposition of Output: UK (Full Sample with Gold)
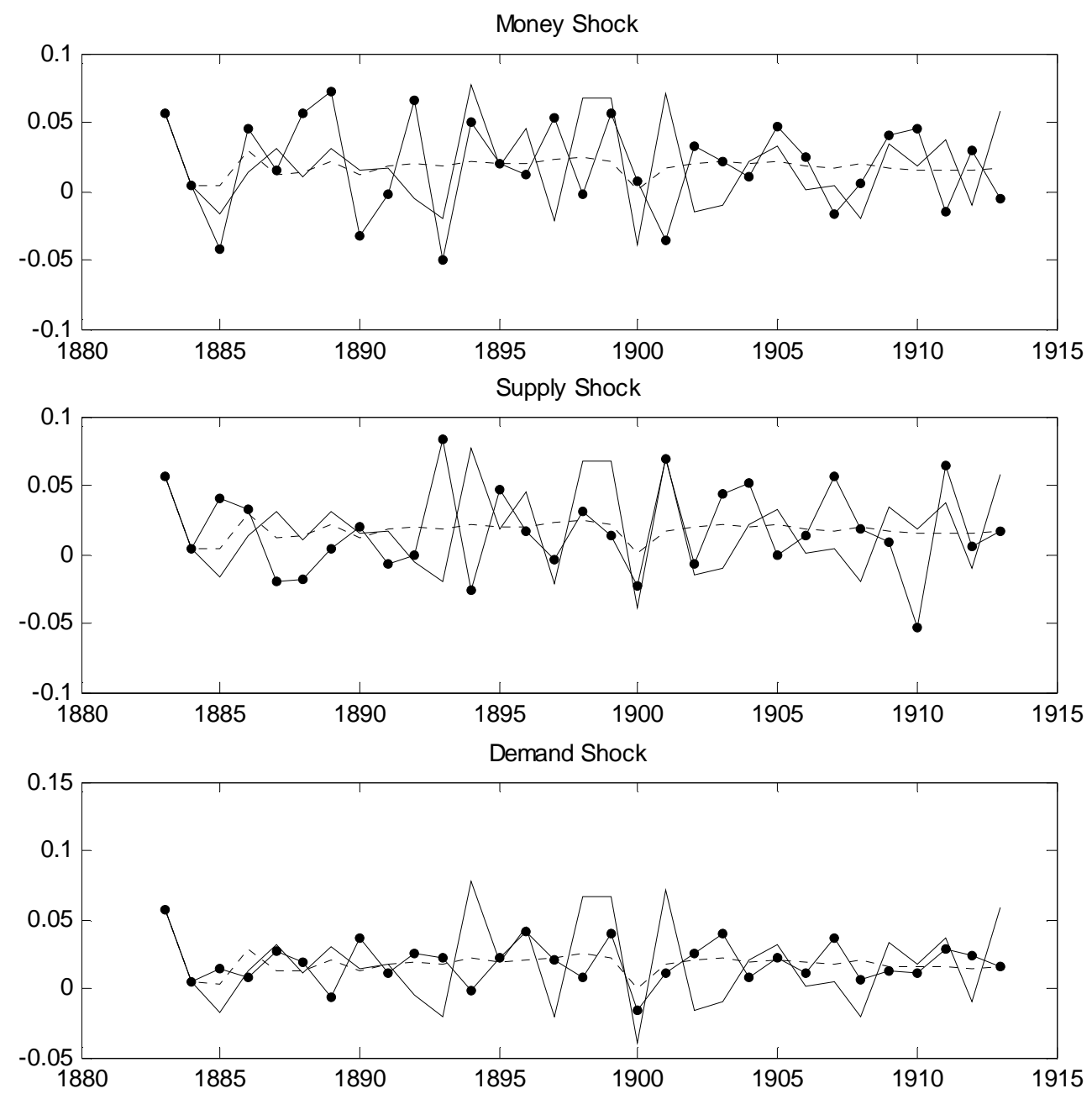

- Actual
$\ldots$ Baseline + Gold Shock
$\ldots$ Baseline+Gold Shock Shock


Figure 22a: Historical Decomposition of Price: Germany (Full Sample with Gold)
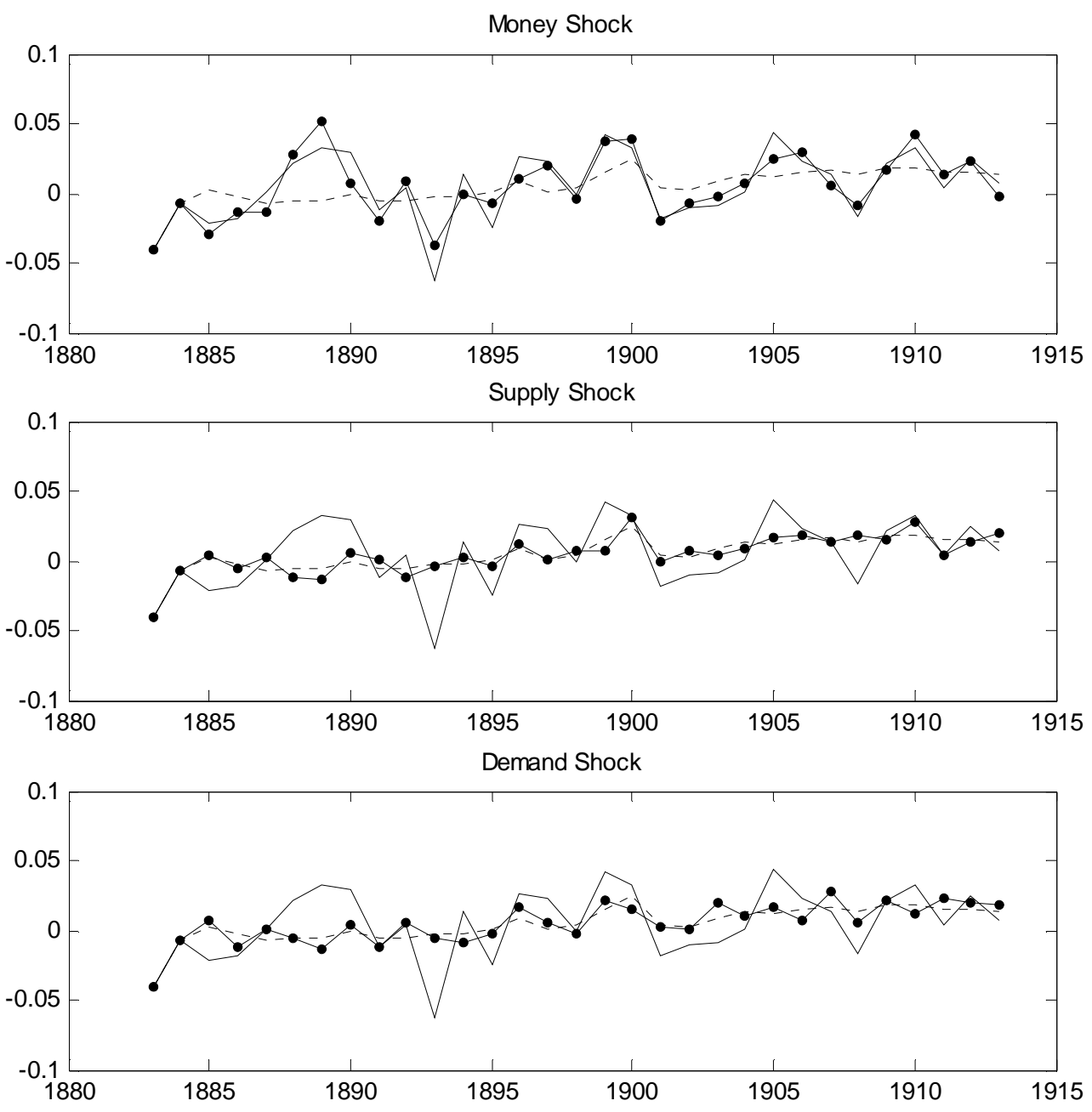

- Actual
$\ldots-$ Baseline + Gold Shock
$\ldots$ Baseline+Gold Shock Shock


Figure 22b: Historical Decomposition of Output: Germany (Full Sample with Gold)
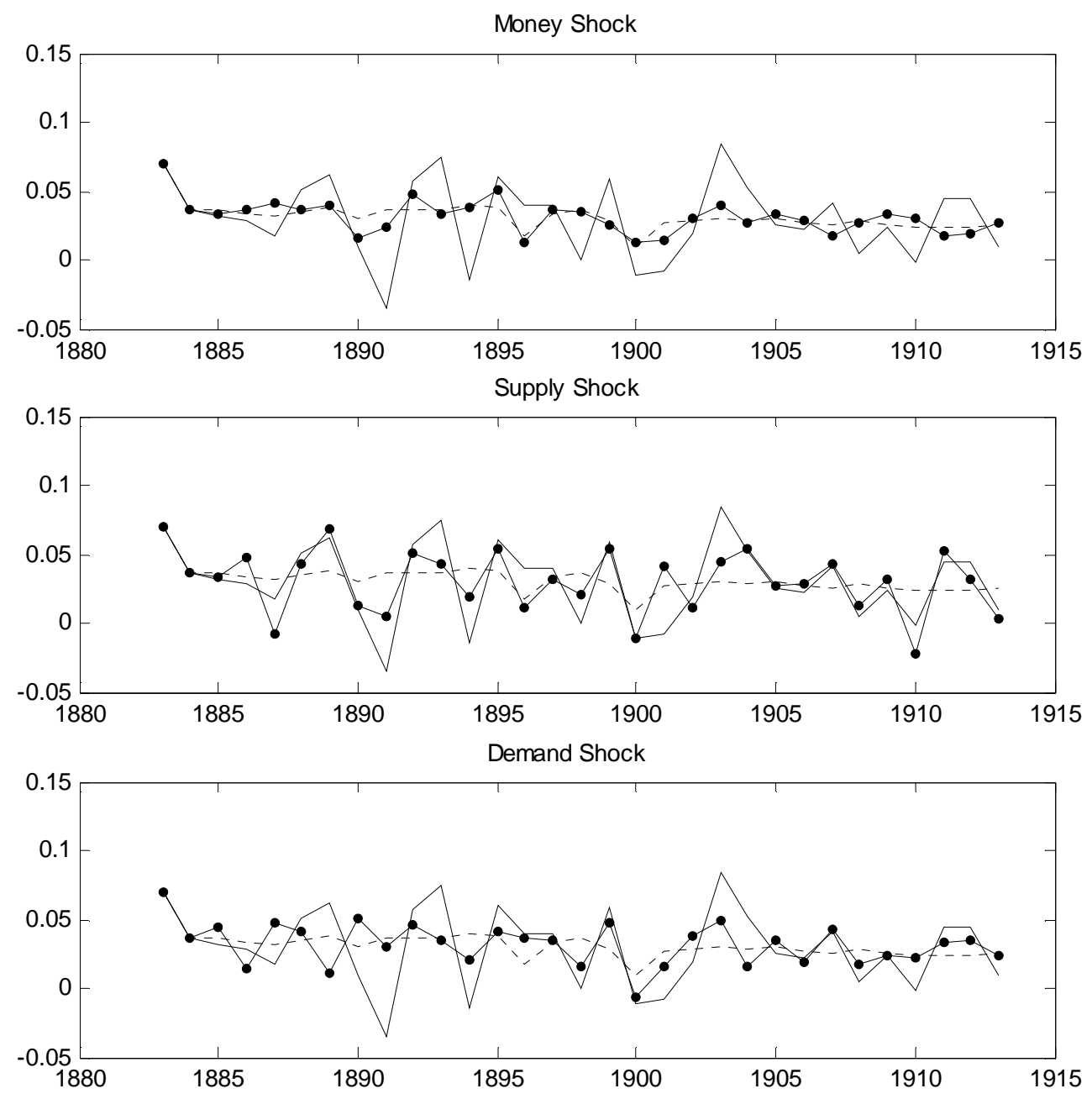

- Actual
$\ldots-$ Baseline + Gold Shock
- Baseline+Gold Shock Shock




\section{References}

Amisano, G. and C. Giannini, (1997) Topics in Structural VAR Econometrics, SpringerVerlag, Berlin.

Balke, N. and R. Gordon (1986) "Historical Data" in Robert J. Gordon, ed., The American Business Cycle, Chicago: University of Chicago Press.

Barro, R. (1979) "Money and the Price Level under the Gold Standard" Economic Journal, March (89): 13-33.

Bergman, U., M. Bordo, and L. Jonung (1998), "Historical Evidence on Business Cycles: The International Experience" in J. Fuhrer and S. Schuh eds., Federal Reserve Bank of Boston Conference Series, Beyond Shocks: What causes Business Cycles? (42), 65-113.

Bernanke, B. (1983), "Nonmonetary effects of the Financial Crisis in Propagation of the Great Depression," American Economic Review, 73(3): 257-76.

Blanchard, O.J. and Quah, D. (1989), “The Dynamic Effect of Aggregate Demand and Supply Disturbances," American Economic Review, 79(4), 655-673.

Bordo, M. (1981), “The Classical Gold standard: Some lessons for today," Federal Reserve Bank of St. Louis Review, 63(5): 2-17.

Bordo, M. and R. W. Ellson, (1985) "A Model of the Classical Gold Standard with depletion” Journal of Monetary Economics (16): 109-20.

Bordo, M., C. Erceg and C. Evans (2000) "Money, Sticky Wages and the Great Depression," American Economic Review, 90(5), 1447-63.

Bordo, M. and A. Redish (2004) "Is Deflation Depressing?" in Richard Burdekin and Pierre Siklos ( eds) Deflation: Current and Historical Perspectives. New York: Cambridge University Press. (in press)

Borio and Filardo (2003)" Back to the Future? Assessing the Threat of Deflation" Bank for International Settlements. Basle April.

Canova, F. and M. Ciccarealli, (1999) "Forecasting and Turning Point Predictions in a Bayesian Panel VAR Model," mimeo.

Craig, L. and D. Fisher (2000), The European Macroeconomy: Growth and integration, 1500-1913, London: Edward Elgar.

Deutsche Bundesbank (1976) Deutsches Geld- und Bankwesen in Zahlen, 1876-1975, Frankfurt: Herausgeber Deutsche Bundesbank. 
Dowd, K. and D. Chappell, (1997) “A Simple Model of the Gold Standard” Journal of Money Credit and Banking (29:1): 94-105.

Friedman, M. (1969) “The Optimum Quantity of Money” Milton Friedman, The Optimum Quantity of Money and other Essays. Chicago: Aldine Publishers.

Holtz-Eakin, D., W. Newey, and H.S. Rosen, (1988) "Estimating Vector Autoregressions with Panel Data," Econometrica, 56(6), 1371-1395.

IMF (2002) “Chapter 3: Recessions and Recoveries”, World Economic Outlook

Kehoe, T. and E. Prescott, (2002) "Great Depressions of the $20^{\text {th }}$ century," Review of Economic Dynamics, 5(1): 1-18.

Kumar, Mannohan, S. Taimur Baig, Jorg Decressin, Chris Faulkner-MacDanagh and Tarhan Feyziogulu (2003) "Deflation: Determinants, Risks, and Policy Options." IMF Occasional Paper \#221.

McCloskey, D. and J. R. Zecher (1976) "How the gold standard worked, 1880-1913" in J. A. Frenkel and H.G. Johnson, eds., The Monetary Approach to the Balance of Payments, Toronto: University of Toronto Press.

Mitchell, B. (1998) International Historical Statistics: Europe, 1750-1993 $4^{\text {th }}$ edn. New York: Stockton Press.

Orphanides, A. (2001) "Monetary Policy rules, macroeconomic stability and inflation: A view from the trenches." Federal Reserve Board of Governors. Finance and Economics Discussion paper 2001-62.

Pesaran, M.H. and R. Smith, (1995) "Estimating Long-Run Relationships from Dynamic Heterogeneous Panels,” Journal of Econometrics, 68, 78-113.

Rockoff, H. (1984) "Some Evidence on the Real Price of Gold, Its Costs of Production, and Commodity Prices" in M.D. Bordo and A. J. Schwartz, A Retrospective on the Classical Gold Standard, 1821-1931 Chicago: University of Chicago Press.

Sommariva, A. and G. Tullio, (1987) German macroeconomic history, 1880-1970: A study of the effects of economic policy on inflation, currency depreciation and growth, New York: St Martin's Press.

United States Gold Commission (1982) Report to the Congress of the Commision on the Role of Gold in the Domestic and International Monetary Systems. Washington DC March. 